University of Rhode Island

DigitalCommons@URI

Open Access Master's Theses

1977

\title{
The Philosophical Problem of Entailment
}

William Augustus Higgins

University of Rhode Island

Follow this and additional works at: https://digitalcommons.uri.edu/theses

\section{Recommended Citation}

Higgins, William Augustus, "The Philosophical Problem of Entailment" (1977). Open Access Master's

Theses. Paper 1557.

https://digitalcommons.uri.edu/theses/1557

This Thesis is brought to you for free and open access by DigitalCommons@URI. It has been accepted for inclusion in Open Access Master's Theses by an authorized administrator of DigitalCommons@URI. For more information, please contact digitalcommons-group@uri.edu. 
THE PHILOSOPHICAL PROBLEM OF ENTAIIMENT

$B Y$

WILLIAM AUGUSTUS HIGGTNS

A THESIS SUBMTTTED IN PARTIAL FULFILLMENT OF THE REQUIREMENTS FOR THE DEGREE OF MASTER OF ARTS

IN

PHILOSOPHY 


\section{ABSTRACT}

This thesis is concerned with the problem of entailment. Entailment is a form of implication, perhaps the strongest found in logical calculi. The development of entailment logics is rather new in the history of logic. The entailment concept has however, been employed for the designation of a strong implication relation between antecedent and consequent. It has been used by some to designate deducibility. There are, however, alternative systems of implication which have been formed and cquated by some to the concept of entaflment. A central question then, is what conditions shall be given to an acceptable statement of entailment, and how does entailment differ from alternative implication systems?

The properties which are inherent in logical implication are shown by a historical sketch in this thesis. The first form of implication discussed is 'material implication.' Material implication as found in Russell and Whitehead's Principia Mathematica is discussed. Following upon this the evolution of strict implication and the 'S' systems of C.I. Lewis and E.H. Langford are analyzed. In the context of these discussions both the common and diverse properties are discussed. It is found that both material and strict implication have internal weakness in so far as both produce implicational paradoxes. 


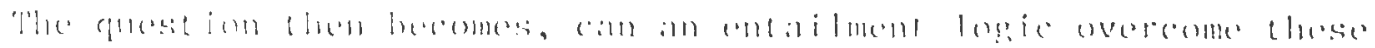

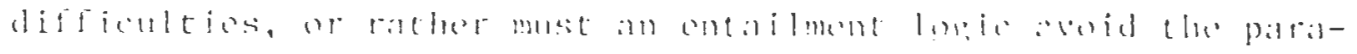
doxes peoul iar to the systems cited?

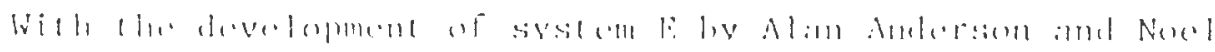
belnap, we find a paralox-free system of impliation. The systom is desionited 'B' For entailment by the authors. Whe system $\mathrm{E}$ is formed by combining the senantical character of "relevance" with that of necessity. It is shown that the system E does not contain the paradoxical theorems nor any analosues of the theorems which give the paraloxes. In the context of this discussion a proper focus is given for several logical terms used in describing the relations between antecedent and consequent.

The resurch of this thesis deals with certain definite problems. Is strict implication the sime as entajiment? According to the research of this thesis this identification is doubtful. of further concern is whether or rather what logically collows from contradiction. This research rejects the claims that anything whatsoever "follows rrom" a contradiction. A final concern of this research is the relation of entailment in modal semintics. This

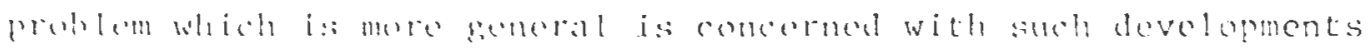
as modal models an the one hand and the nature of possibility on the other. It is found that an impossible proposition need not have the essential form of a contradiction. 
IMBLE OF CONLEITS

CIMPTER

PACE

I. INTRODUCTION . . . . . . . . . . . 2

II. STRICT IMILICATION ............. 6

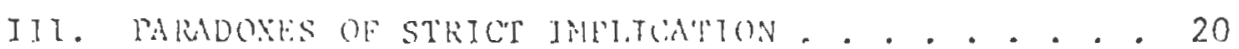

IV. TUE SUSTlM 'E' OF ENTIILAR' . . . . . . . . . . . 37

A. The Development of System T. . . . . . 37

B. Conclusions of 'E'............ 48

v. COnClusion ................. 55

VI. BIBLIOGPAPIYY . . . . . . . . . . . . 65 
$p, q, r$, etc.

$A, B, C$, etc.

$\mathrm{V}$

-

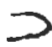

$-3$

$\rightarrow$

$\equiv$

$\equiv$

$\exists \mathrm{x}$

$\square$

L

N

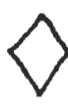

M propositional variables

metalinguistic variables

wedge, sign of disjunction

dot, sign of conjunction

material implication

strict implication, Lewis and Langford

entailment sign, Anderson and Belnap

equivalence

strict equivalence

existential quantifier

necessity, Lewis

necessity, (conventional sign)

necessity, Carnap

possibility, Lewis

possibility, (conventional sign)

sign of negation 
INTPOกI'Th

The purpose of this thesis is to malyze the lorical relation of "entailment'. "ore precisclv what is vanted is an expleation of entailment as a form of fimplication. The problem centers on

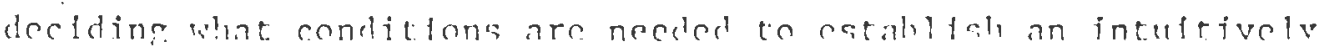

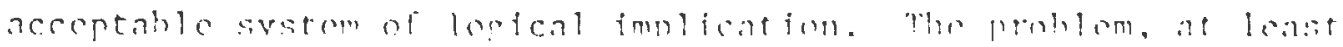
on face value, is not at all clear-cut. For as is comonoly known, there are several forms of fmolieaterl. The most Fumbamental and rost common is 'material impljention'. Nil the nther hand, thete is the more sophtsticated system of 'strict jmnlication', wheh is develoner emploving modility. There are furthermore other systems such as the sisetem 'F', where 'F' stands for entaiment.

The problom of implication depends on the combltims for estahlishing the relation in question. The min components emploved destemate aceordinsty the antededent, the loniral symol for impleation and the conscquent. Uhen prosented with some such 'form' as pつ 4 , certain descriptions hecome apnarent. The antecedent, here $p$, acts as the premises, while 7 acts as the conclusion of an arsument. The imnlication sombl dosisnates that p impless 4 , and that the anteresente is the remonds for the asscrtion of $q$. Put how shali ye real such a formula?

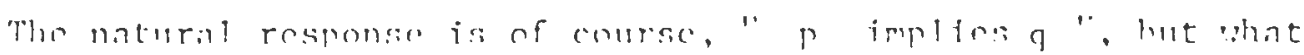

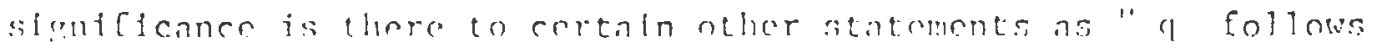


Erors p", or" r is lerivohie from r", and still further, "P entolls $n$ i?

The problein is, that in cortain formalisels the romerrings just cilod are not a ways intuitfvoly acoptahle. Tn the system

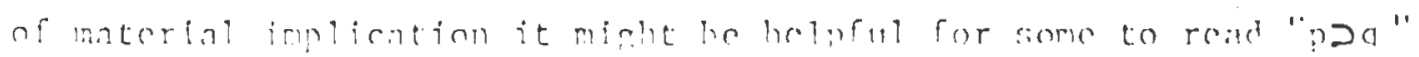

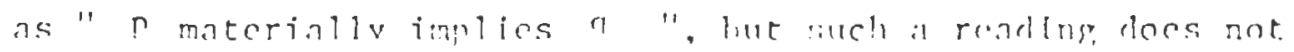
alderss the undorlviur lasurs imnlicit in the phllesophical concoption of implication. In the sustem of "material Implication" or any sustem constiructed nut of " $"$ ", when flo horseshov symbel "D "is ecfinol הa:

$$
\Gamma \supset \eta=d r \sim p \vee \eta
$$

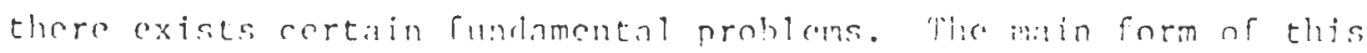
problem oceurs upan the derlvating of "piratoxes". The mast

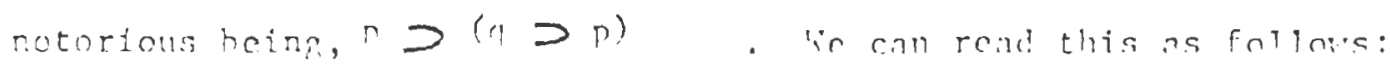

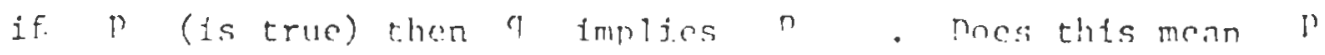
"follows from" $\pi$ in anv acceptahlo sense? Mhe most obvinus critjcism is that therr is a fallacv of rolovance, that is to say, there is no olvious sennectom hetwern the antecelent anel the

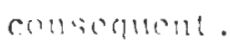

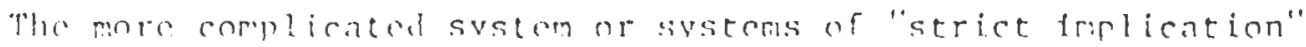
emplov a more sophisticated verston of implication. The sustem nf "strict implication" chniovs the sumbel -3 , colled he somo the fish-hook. In this svetem, r -3 r, raisl " r strictly implics ?" emplovs the morit consept of nesessity. The defindtinn - 
is:

$$
p \rightarrow q=1) E \cdot \sim \eta(p \cdot \sim q)
$$

The ahove definftion states that for $p$ to strictly imnle 7 , it is not possihlo for $p$ to he true and a fales. The definttion sn siven allowes tie desirnhle fonture, that there is a necessary counection heteren antecedent and consenuent. The system so constructed doos bosever have its problometical thenrems, such as:

$$
\text { q } 3(p \vee \sim \sim p) \text {. }
$$

The ahove save fhat a mecessary proposition is entailnd he any pronostion. Wut dons a necossary nroposjtion "follow feno" any proposition?

In the test of what follnes, the sustem of "strict fmplfantinn" and pertinent materials whl he discussed. The distinctiveness of

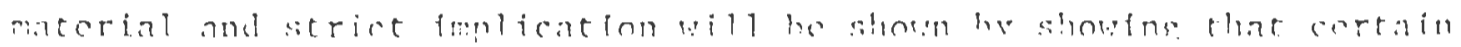
theorems of material iminlication are mprovable as theorens of "strtet implication". Following unon this, the "paradoxes" of "steict implication" will he discuased. In the attempt to eliminate

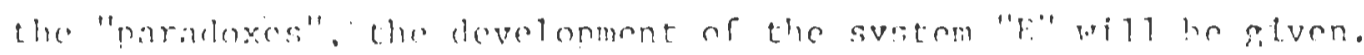

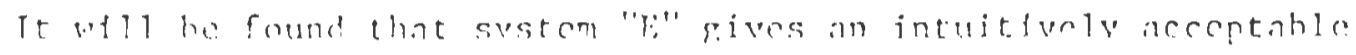
cunrossion to tenlfention, or enther, menilment. We shall find

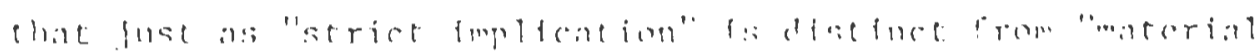

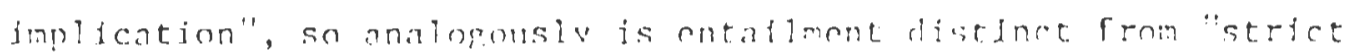
implication".

Tn wht follows, small leters; shall ropor to propositional varables wite capital letters refor to retalingutstic expressions. 


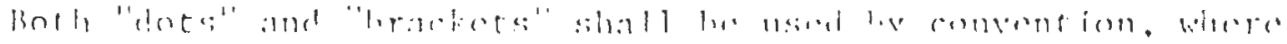

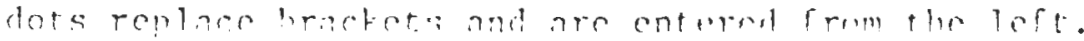


CHAPTER II

STRICT IMPLICATION

The pioneer work in the development of systems of strict implication was done by C.I. Lewis. Further advancements and progress were made by the collaboration of C.I. Lewis with C.H. Langford in the co-authored book entitled Symbolic Logic. Strict implication is a species of "modal logic", but more precisely, of modern modal logic, inasmuch as the notion of modality, in principle, is nothing new. In the history of philosophy, such thinkers as early as Aristotle had recourse to modal notions, 1 even Kant went so far as to make modality a category. ${ }^{2}$

Modern logistics, however, had with the development of Principia Mathematica, ${ }^{3}$ access to more rigorous and in effect more precise machinery for analysis, the principal benefits being the advancement of axiomatic techniques in logic.

In the context of Principia Mathematica ${ }^{4}$ or more precisely in its formal symbolism, there occurred the $\overline{1}$

Aristotle, Prior Analytics, passim. 2

Immanuel Kant, Critique of Pure Reason, trans. Norman Kemp Smith (New York: St. Martin's Press, 1929), p. 239. 3

Alfred North Whitehead, Bertrand Russe1l, Principia Mathematica to 非56 (Cambridge: Cambridge University Press, 1970), preface V.

4

Ibid., p. xvi. 


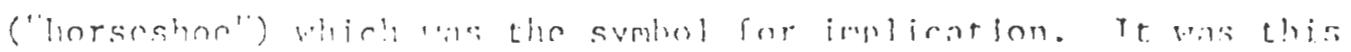

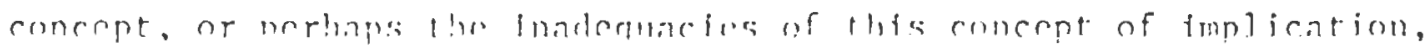

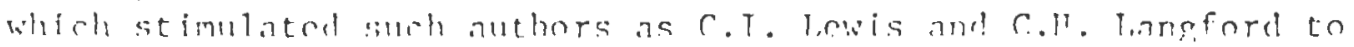
explore the nature of implication. In P.". the definition of

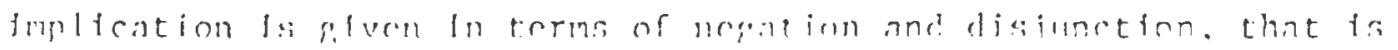
at $\star 1 . n\}$ in P.". , se rin!:

$$
\Gamma \supset \Gamma \cdot=\sim \Gamma \vee n \Gamma r
$$

likewise, wo find the statcments; (as cyplanation). 'Tn

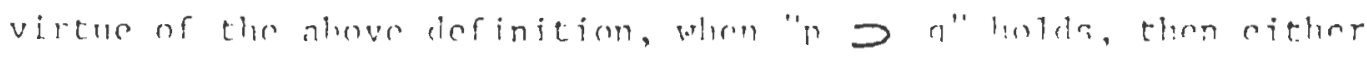
$p$ is false or $n$ is true: hener. if $n$ litrus, 7 must he true. Thus, the above definition nreserves the resential charactoristic of implicatinn: it gives, in fact, the most soneral meaning compathle vith the preservatom of this characteriste." The above-mentiomed imoliention is of courso paterial implication. us shnuld note in passing that P." nlen incorporated the ides of

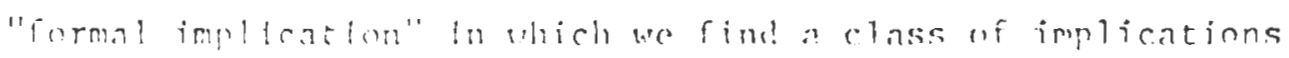

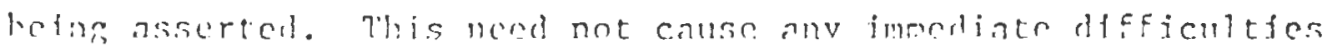
ror the discussion wheh follows, for the simple roason that manv of the propertjes of this relation are analopous.

In wht follows. soveral pronertins wich charecorias matorial

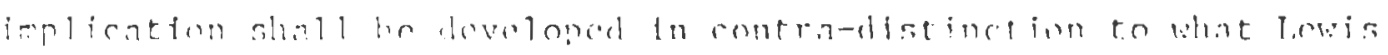

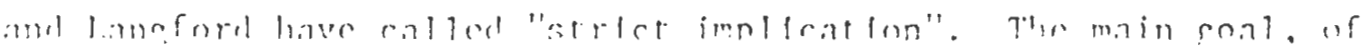

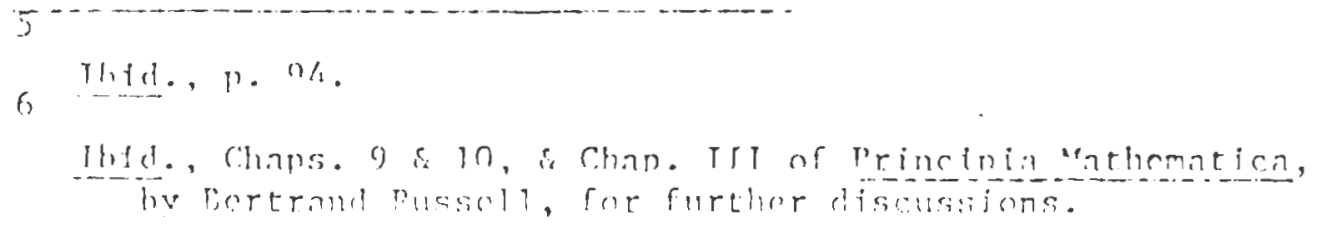




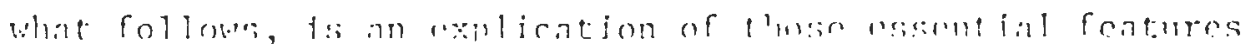
possessed hy striet implication.

The following spencral statemonts are offered as alds in distinguishing the tun systems of implication.

1) "Striet implieation" is resimmel to renrosint symolienlly the relation "i is deduclhle rrom ")".

2) "alaterial irpblication" is cssentfally a relation betwern tro propositions determined hy cxtensional fentures.

3) "strfet irplication" is formally slistinguisind from "nontertal implication" by the follumine postulate:

$$
(\exists n, \eta): \sim(n \rightarrow \eta) \cdot \sim(n-3 \sim q)
$$

The Pirst nhservation is readily sern to be a rendering of What lowts and taneford perceive to be the essential feature of strict implication. The fden of deduchllity, as the fundamental foature of strict implication is th accord wich the hasic mot tue that a proper format for an mplicative calculus shomld canture a strone losical relation hetwoen antecedent and ronsoguent. In what follows, we shall observe the developinent of strict implicntion, form a formal point of view, with the aid of modal notions. In contrast, however, the sernnel oiservation lavs cmphasis on cxtensfomal fontures, that is, truth vilur. It is of inmotance th note that material implication rests upon chis foature nlone and In so far ns prian fmportance is placed on such truth value comblitinus, only the harest sonse of lorical consequence can be incopporacel. This can he seen from the fact thint the sumber "D" is a truth functional connective wich can he connletely defined by a truth table. In thls dofinition. Wich corresponis to that

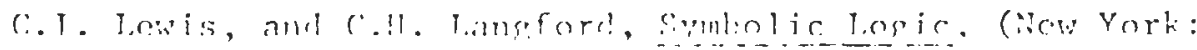
Dover lrosss, 1050), 11. 179. 


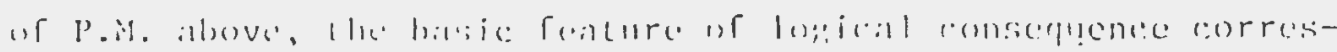
ponds to the most adementary property of impitation, that being, that a false proposition not be inforred from a true proposition. The rirst two observations ahove are not sufficicht to

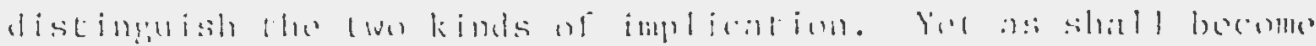

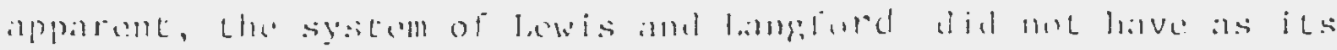
whect the of imination of extonsional foutures in their system, but rather an effective blending of the general system of truth functions with that of stronger logical notions. The third observation above we shall. find is sufficient to distinguish the Lwo forms of implication. To arrive at this postulate, however, we shall have to cmbark on a mure indirect course, so as to anplify. as it wore, deducibitity and trulh functional inference. It shal] also be neressiary to intreduce modal ronecpls to expliante this postulate.

We may begin by citing two forms which accur in truth functionil propositional logic:

a) B is validly inforred frum $\Lambda$.

b) $A$ malcrially junlies $B$.

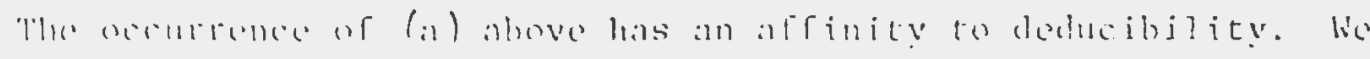
an wetrat the andition that by some mode of inference, that $\Lambda$ being asserted, we are entitled to assert B. For example, if A were to stand for "p" then "puq" would validly be infurred as B ly the log:ind low al adsition. In two-yalum propositional logic Lhis is juluitively obvioms. What makes this ohvious is the

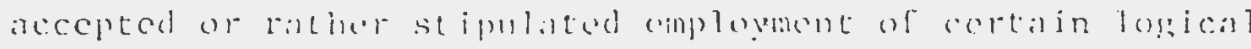


constints. The truth combitions for the "v" (wedpo) are sinuly that onc of the disjuncts be true for the whole proposition "puq" to be true. The point to all whis is simply to show that there is indect a senso in which deducibility is a perperty of such truth luactionil systoms. But what is to bo further moled is that che point was made presupposing "assortien", that is th say lie did nol

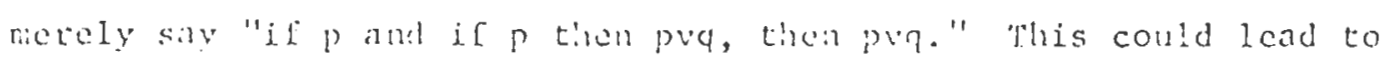
the familiar paradox of Lewis Carroll, in which the tortoise insisted to Achilles, "But that's "nocher condisional", "ihe problem is: do we have in our system a symbol wich represents the relation "B is deducible from A"?

Here we load to (b) abuve in ihich we fild an implica-

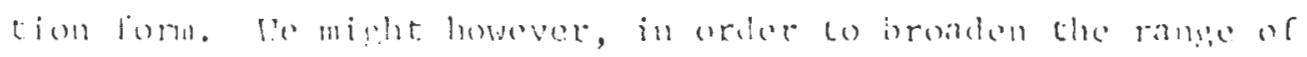

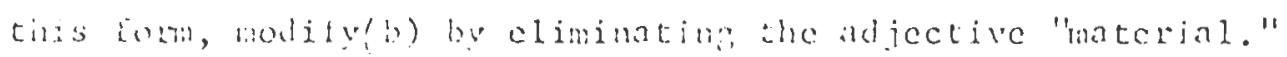
The result would simply be "A implics $B$ " and stand for a truth functional implication. The conditions upon which suci implications rest are not adequate to satisfy tise relation"7 is deducible from p," because the truth implication is dependent on a functional relation between the possible values of the nropositional viriables. The resuli is that such "treth implications"as 6.?. Lewis calls chen, must be too inclusive in their meaning to be equivalent to " 7 is deducible from $p$," in as liniri a: tine relation holds whonever both $p$ and $q$ are true.?

\footnotetext{
3 Lewis carrol1, Mim: Complete horks of Lewis Carrol1, col. A. Vool lcute, What The Tnrtoise Silid to Achilles (Hew York: Random licuse, 1uc.), p. 1225 .

9 Lewis airl lankford, p. ?3?.
} 


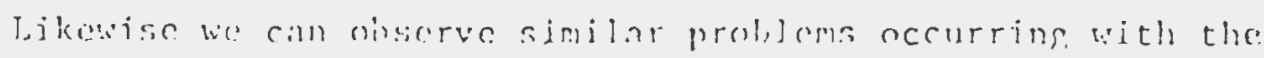

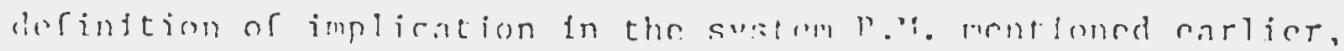
whech is essont laluy the same. Comstelor for instance the proposi-

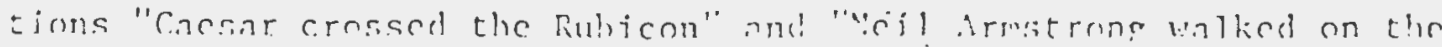

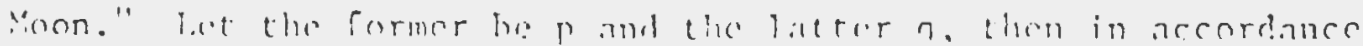

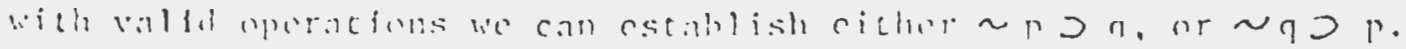

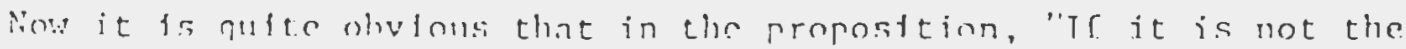
case that Cinesat cerosed the Rubleon, then Nefl Armstennr, vallend

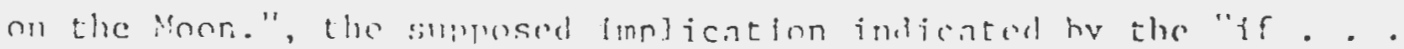
then . . "Falls cusn to approximate a relation hetwern antecedent anc! consequent such that "li is deducllis from d" vot it deses desssonate in accordance with stinulated comventions, "A nutcrially implies B." shether raterjal irulication is a kind of implication at all

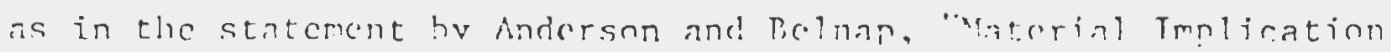
is not a 'letud' of implication. or so we hold: it is no rore a

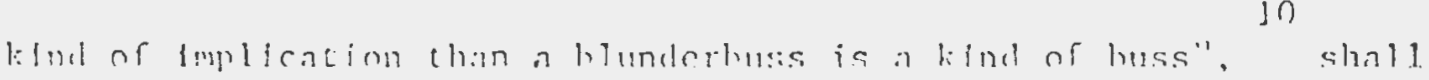
he lort to the roarior.

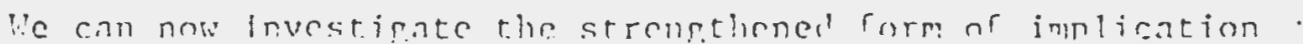
Whici lowis ond lanefnet colled "strict impliration". This form nf

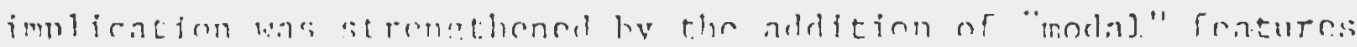
rible ore non-extensinnal. That is to sav, the sipn for sterict.

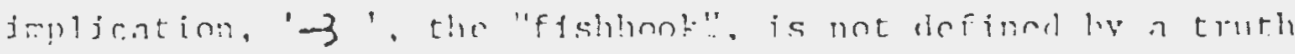
tahle, hut rather is doffned in terms of "y" 'possibility', where possibilicy is o mnualle operator nuer truth functinnal statements. 10

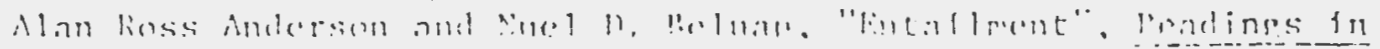

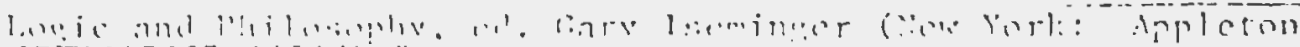

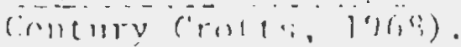




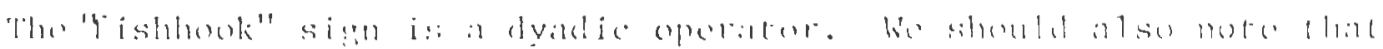
possihility is interdesinable with "nerensity" designatedel "lo" by convention, and that a system whose primitive modal notion is possibility is saje to be M-based and similarly at systom may take

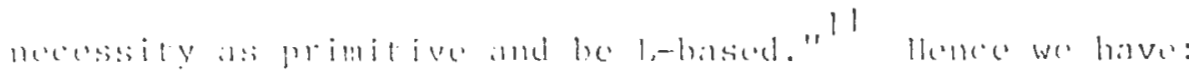

$$
\begin{aligned}
& M P \equiv \tau \sim P \\
& L_{P} \equiv \sim i \sim P
\end{aligned}
$$

Lewis and langford introduce a further molal notion into their system of strict inplication, that is, the comcept of consistency. Ther proposition "p is comsistent with q", symbolized hy "poeq" has the intended interpretation that with oither p or q sorving as a pre-

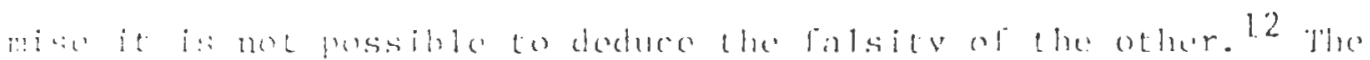

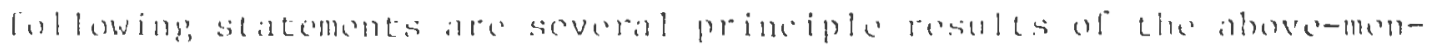
tionced modinl notions. in lewis and langrord's Symbolis logic, we hive:

$$
11.02 p-3 q=. \sim 19(1, \sim q)
$$

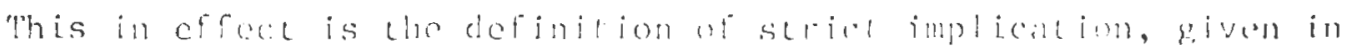
terms of negation, possibility and product. To say q is deducible from p silys thate it is not possthle for p to be true and a false.

$$
17.01 \cdots c_{1}=\sim(p-3 \sim q)
$$

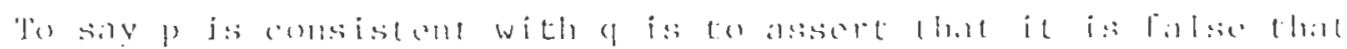
Lhe negale ion of q he deduced from p.

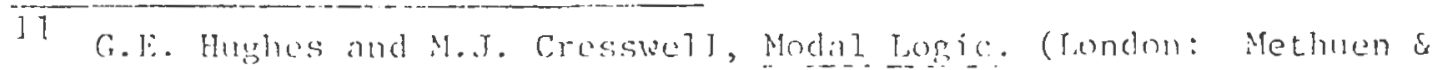
(i)., l.tol., 1968), r. 26.

J2 Lowis and Lingiford, p. 153.

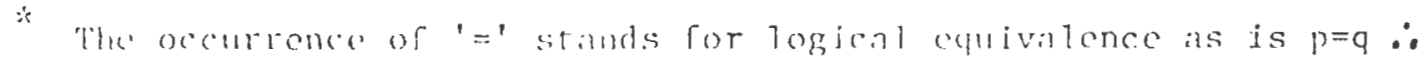

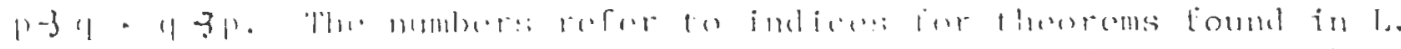

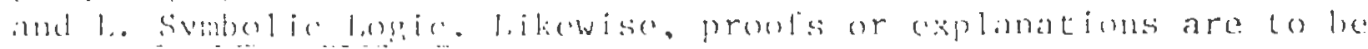

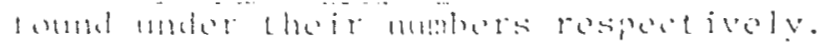




$$
17.12 \%-3 \eta \cdot=\sim(m \sim 7)
$$

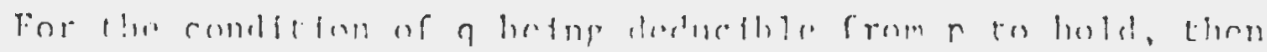
n and the neration o? a are not consistont.

$$
18.1 \quad \because p=.(n n n) \cdot=\sim(n-3 \sim n)
$$

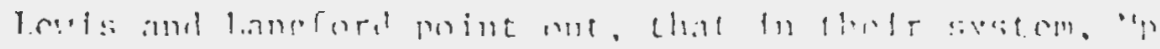

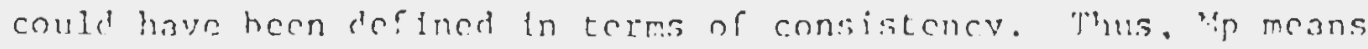

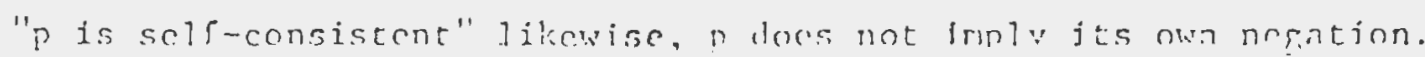

$$
13 . ! ? \sim p \cdot=\cdot \sim(m p)=n-3 \sim n
$$

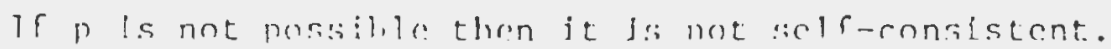

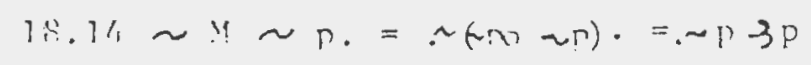

Tf $p$ is necossary, then jts nosition is not solf-ennststent.

"hoving, introbuced tire prinftive fiens and concepts of

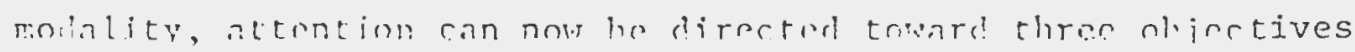

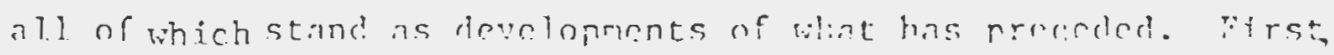
re can accentuate the inpical consmonences of the cxistenes

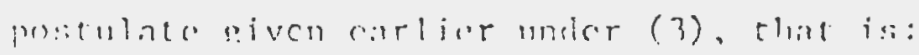

$$
? n, n(\exists n, n): \sim(n-3 n) \cdot \sim(n-3 \sim n),
$$

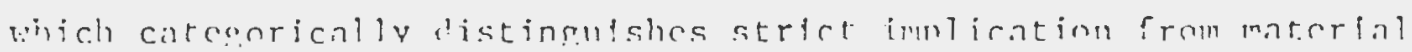
irnlication. Following unon this ue can secombly aralyac the smployecent of sirict implication. Finnlly, we can procons to the parainxes of strict implication and the logical import of such

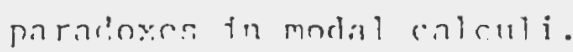




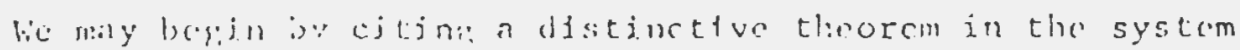
of strict tmplication. That is:

$$
12.31 \quad p \rightarrow q .-3 \cdot \sim(p \cdot \sim q)
$$

This theorm states that if $p$ strictly dmples $q$, then that it is not

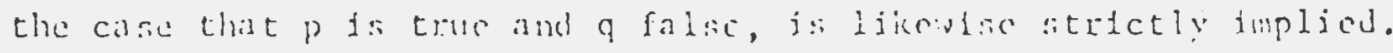
What is important ahout this theorem ls that les converse which would be

$$
\sim(p \cdot \sim q) \cdot \rightarrow, p \rightarrow q
$$

cannot hold. If the converse were to hold, then a frec interchanfe of "つ" for " $\rightarrow$ " would occur, renderiny, strict Implication a redundant form of naterial Implication. Likewise, if the converse of 12.81 were to hold tinen all the modal notions would be reduced to the simpler cxtensional constants 1.c., poq would be pq, $\sim$ ipp would be $\sim p$, etc... 13 This however, is contrary to the system, for although we have theorems of the form

$$
18.4 \quad p \rightarrow \text { iip }
$$

that is, if $p$ is truc then $p$ is possible the converse; $p$ is possible implies $p$ is true is certainly not valid. Postulate 20.01 excludes the frec interchange of " $\supset$ " for " $\rightarrow$ "and problbits the reduction of molal onerators to the extensional constonts. postulare 20.01 allows that there be two propositions such that, if $p$ be one of them, then it says nothing of the truth or falsity of the other, i.c., q. What fis to say, two propositions can at once be consistent 33 Levis and Lingiord, p. 173. 
and independent, for "p is consistent with q", poq is, by 17.01 given earlier, equivalent to $\sim(p \exists \sim q)$; that $p$ and $q$ are independent is expressed by $\sim(p-3 q)$ which states $q$ is not deducible from p. Contrasting the above distinctions with the theorem

$$
15.72 \mathrm{p} \supset \mathrm{q} \cdot \mathrm{v} \cdot \mathrm{p} \supset \sim \mathrm{q},
$$

we find that if strict implication were to be identified with material implication, as in the case in which the converse of 12.81 were to hold, then 15.72 would be an exact contradictory of $20.010^{14}$ In terms of material implication, two propositions cannot be consistent and independent as indicated by 15.72 , ergo the two kinds of implications are distinct if the system is consistent.* Proceeding to the second objective, that is, the nature and function of strict implication, we may begin by reflecting on two points mentioned earlier. To begin, we observed under (a) and (b) above, two logistic forms which characterize two important points of a logistics calculus. One emphasizes the act of making an assertion as in the case in which a conclusion is asserted on the grounds of the premises, and the other cites a relation of "implication" which holds between the antecedent and consequent. The first pertains to inference and generally speaking does not offer as much difficulty as the second. In fact, most penetrating

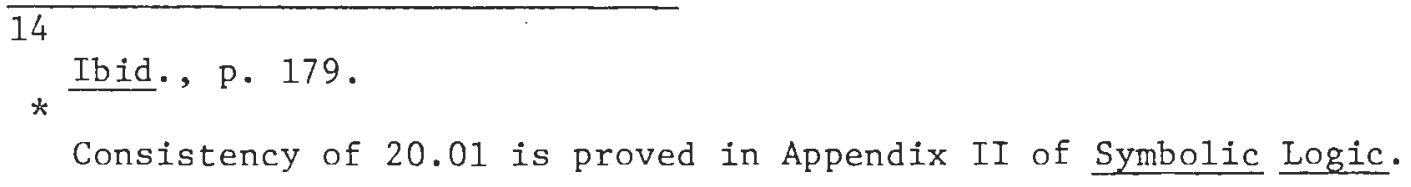


problems of inference revolve around finding criteria for deciding what is to be a valid inference. The problem in this form sha11 be postponed until the discussion of the paradoxes of strict implication. However, the logical notion of inference is germane to the concept of deducibility, in as much as we shall find it very advantageous to subjugate a) under a modified form of b).

To effect this change, we shall want the concept of a valid inference of $B$ from $A$ to correspond to a valid deduction of B from A. As for b), which was originally "A materially implies B", we shall stipulate the modification, "A strictly implies B," with the intended meaning that B is deducible from A. In accordance with these points, we may now ask, has Lewis and Langford's calculus of strict implication successfully achieved this result? We can give an affirmative answer, in so far as the above-mentioned distinctions give insight into the usage of a certain logical symbol, that is, what was designated by the "fish hook." To explicate the usage of this symbol we shall need to appeal to the concept of tautology. Similarly, we shall find justification for making strict implication an extension of truth functional logic, that is, from Lewis and Langford's points of view.

Informal1y, we shall define a tautology in the propositional logic as a formula which is logically valid. That is to say, a tautology has the value $T$, or 1 from a syntactic point of view, for every possible assignment of values to constituent 
propositional variables. A tautology is true by virtuc of the form of the statement. A tautology is sald; therefore, to be a necessary truth which is in contradistinction to a proposition which is contingently true as in the case when some truth function gencrates a true proposition by a possible assignment of truth values. Consider some truth functional implication, say, $p \supset q$, this need not be tautalogical but nevertheless if $p$ is asserted, then on the intended interpretation $q$ must be asserted. Let us generalize this scheme as $A \supset B$ where both $A \supset B$ is asserted, and $A$ is asserted as laws of the system, $1 . e$. , as tnutalogical, then is likewise must be asscrted. What we have $1 . s$ a distinction between $p \supset q$ as true and $A \supset B$ as tautalogical in which case if we are glven two premises $p$ and $p \supset q$, we can infer $q$, but this is now a special case of $A \supset B$, because $(p(p \supset q)) \supset q$ is now a taitology. 15 This is precisely the point Lewis and Largford have in mind when they state: whenever any truth impilcation, pIq, expresses a tautology (1s necessarlly true) the relation $p-3 q$ holds: when $p I q$ is true, but does not express a tautology, $\mathrm{p} \rightarrow \mathrm{q}$ does not hold."16

Several examples will exhibit more clearly the employment of strict Implication. Consider the following two reiums for coingarison: "?

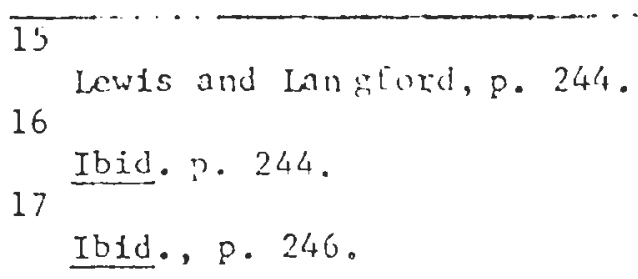


I

15.21 p. $>$ q $q$ p.

$15.23 \sim p . D . p \supset q$

$15.31 \sim(p \supset q) . \supset$. p $\supset \sim q$

$15.4 \ln (p \supset q) . \supset . q \supset p$
II

$$
\begin{aligned}
& 15.2 p .-3 . q \supset p . \\
& 15.22 \sim p .-3 . p \supset q . \\
& 15.3 \sim(p \supset q) . \rightarrow . p \supset \sim q \\
& 15.4 \sim(p \supset q) .-3 . q \supset p .
\end{aligned}
$$

Colmu I pives propositions derived in the syscom of Materfal Implication while proposftions under II are derived in the system of Strict Implication. The employments of " $\supset$ " under column I which are tautological are capable of being deduced in the system of strict foplication whereas employnents of " $\supset$ " which are not trittoloy,ical, that is, cases which lack nsacteton connot be replaced by " $\rightarrow$ ". In fact, if in Column II, the occurrences of " $\supset$ " were replaced by " -3 " the theorems would be false. 18 whe then can be concluded about the nature of strfet implication?

Wth respect to the systems developed by Lowis and Langford we can see an explication of valid deduction. This occurs, however, with respect to extensional systems in so far as the relation of strict implication holds when valid infercnce in some system is possible. This is the most fundamental use of strict implication, although it would be misleading to limit the notion of strict implication to the expression of properties of truth-functions. That is to say, we would not want to obscure the importance of modal operatorz in their own right, so to speak. Strict implication does however, give an important distinction between the casc in which $p \supset Q$ holds and the idea of "q's jeductulitty from p". Consider for instance 15.2.1, "If $p$ is true, then $q$ (any 
propostefon) fuplees re", which ta we of the lambltat parmboxes of material implication. Strict implication does not allow the consequent to be equivalent to "p 1 s deduclule from q" although the consequent as a whole is strictly implfed by the antecedent as in 15.2 given under column II above. 


\section{CHAPTER III}

PRIRAOXES OF STRICT IMPLICATION

To this point the symbol "-3" has been interpreted as "strictly implies" but as wll soon become obvious therc are additional senses associated with this symbol. Firstly, there is the ancept of 'deducibility" briefly touched upon earlier, and endorsed by many logicians as a meaning for "strictly implies." There are likewise other verbal statements for " $p \rightarrow q$ " such as "q is deducible from $p$ " or "q follows from $\mathrm{p}$ " and perhaps the most fundamental of a11, "p entails q". A real problem and controversy enters at this polnt as many prominent logiclans take head to head opposing stances. The key to the issue centers on the answers to thr question "Is strict ioplication the same as entallment?" The appearance of the paradoxes of strict implication occuples a central role ln tils controversy in as much as their occurrence fa claimed as cvidence for both sides!

We should note that the theorems to be given directly are dependent on a formal context. That is to bay, the several expressions whlch are considered paradoxical occur in some formal system and as such are derlunble in some system. Here are four important fommale lor consideration: 19
1.) $(p . \sim p) \rightarrow q$
2) $q \rightarrow(p \vee \sim p)$
3) $\sim M_{p} \supset(p \rightarrow q)$
4) L $q \supset(p-7 q)$

I9lughes and Cresswell, p. 335 . 
Furthermore, we shall put forth two basic forms of the paradoxes which occur in the systems of Lewis and Langford. They are

$$
19.74 \sim \mathrm{Mp} \cdot 3 \cdot \mathrm{p} \rightarrow \mathrm{q}
$$

which states that an impossible proposition strictly implies any proposition and,

\section{$19.75 \sim \mathrm{M} \sim \mathrm{p} .3 . \mathrm{q} 3 \mathrm{p}$}

which states that a necessarily true proposition is strictly implied by any proposition.

The formulae (1)-(4) are more general, although basically the same as 19.74 and 19.75 which are somewhat restricted. The difference is dependent upon the modal notion involved. Formula above states that a contradiction entails any proposition while (2) states that a proposition of the form ( $p v \sim p$ ) follows from or is entailed by any proposition. Formula (3) states that an impossible proposition implies any proposition, and (4) states that a necessary proposition is entailed by any proposition. The modal variance between $1-4$ and 19.74 and 19.75 rests upon the restricted sense of impossible and necessary. For Lewis and Langford, "p is impossible" means "p is not consistent" while "p is necessary" means "the denial of $p$ is not self-consistent." "Necessary truths so defined, coincide with the class of tautologies, or truths which can be certified by logic alone; and impossibie propositions coincide with the class of those which deny some tautology."20 The occurrence of the impossible in (3) admits to a 20

Lewis and Langford, p. 249. 
broader scope that is, it is not limited to propositions of the form $p . \sim p$, 1ikewise in (4) necessary is not 1imited to (pv $\sim \mathrm{p}) .21$ Admitted1y, this picture does not have the quality of crystal clarity, consequent $1 \mathrm{y}$ a minor digression is in order.

The questionable features of this scheme of modality rests upon the interpretation of both impossibility and necessity. We are faced with the problem of deciding whether al1 impossible propositions are in essence contradictions, and if so, how so. Particular1y, we must take notice of the claim cited above that impossible propositions deny some tautology. We sha11 want then to deal with the context of modal-logical truths on the one hand, and applied modal logic on the other.

Brlefly, we may first take note of the fact that there are many moda1 logics. Logics which dea1 with necessity and possibility are conveniently called alethic modality, of which the "S" systems are most common. The S systems are constructed by building upon a set of postulates. When further axioms are added, the systems are said to be stronger. ${ }^{22}$ For instance we have the system 44 by adding to certain postulates the axiom LP 2 LP while 55 is obtained by adding the axfom Mp $D$ LMp to the same set of postulates. The system S5 however contains the system S4 because the axiom LP LLp can be derived in S5 therefore S5 is said to be stronger. The development of such systems often results 21 22

Hughes and Cresswel1, p. 336.

Ib1d., pp. 341-342. 
from a curiousity over the logical structure which is the product of such an inquiry. It is not; as it were, a brilliant intuitive insight into logical truths which is the impetus, rather that the nature of such 'modal laws' generated by some system generally rests in a mist of controversy which is the impetus.

The common view that logical analysis laws bare the structure of reason is not forsaken however, as logicians and the like attempt to find application for many of these newly formed logics. A.N. Prior, for instance, attempted to accommodate his tense logic to the structure of the 54 modal logic. 23 "I shall now show that tense logic as I have described it, is a modal system, and that if we define M (or 'Possibly') as 'It either is or will be the case that', and I (or 'Necessarily') as 'It is and always will be the case that', these operators will meet Lukasiewicz's conditions for being modal operators and, furthermore, will have all the formal properties of the $M$ and $L$ of the Lewis system 54.24 The point we care to make can be represented diagrammatically as follows:

I $\dot{1}$

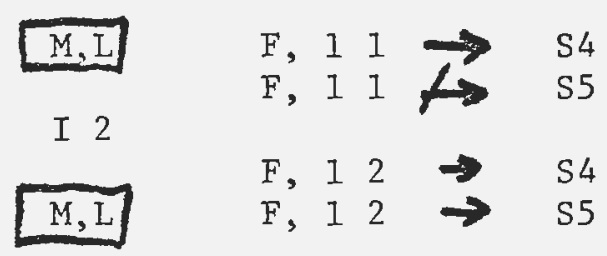

Her $I I$ and $I 2$ are interpretations for the modal operators $M$ and $\mathrm{L}$, while $\mathrm{F}$ is some formula constructed in them in accordance with the interpretation. The arrow indicates that some formula in

\section{3} 24

Hughes and Cresswell, p. 263.

A.N. Prior, Time and Modality (Oxford: Clarendon Press, 1957), p. 17. 


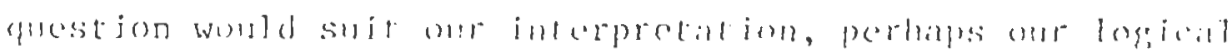

intuitions, while a bar across the arrow would reject the intended inlerpretation with respect to the ropical structuce in question i.e., the Sit or S5. Tn the tense-logic of A.N. Prior for instinue, the lirst ass above wuld exumlify the rejection of the s5 axion Mplip for on that interprotation we wuld have, whatever is or will be true' is amb always will be (true or going to be true) and this is false in the case in which p describes a process which has not yet but will semedity stop for gonel. 25 The secound case ahoure could be an altornate interpretation which employs the s5 structure

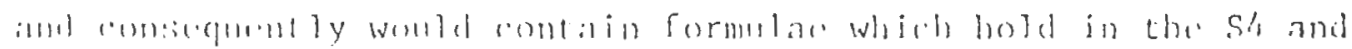
in 2 he $55 . *$

Now to return to the original line of thought we can attempt to clarify the concept of impossibility. The position given by C.I. lowis insigts that impossible proposit inus deny some tauteology and since a tantolegy is a statement which is truc for all value assignments it is quite obvious that a denial of such a statement shall te-

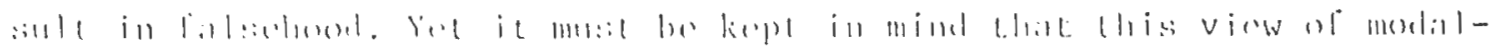
ity am antalimm (strict inglication) was croated on an extensional base of propositionil Loric, consequenty impossible peopositions 25

Thid., p. 24 .

$*$

Note: Prior's use of sh was avontmilly rejected by him. of

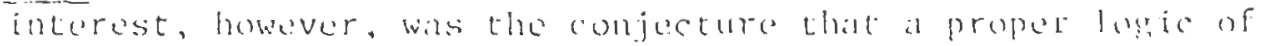
time nust accomut for tine as discrote amd time as continuous.

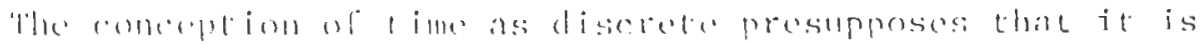

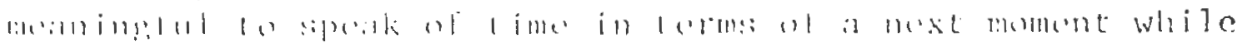

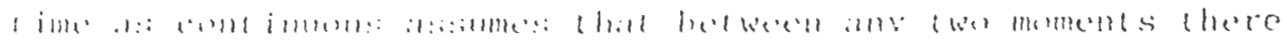

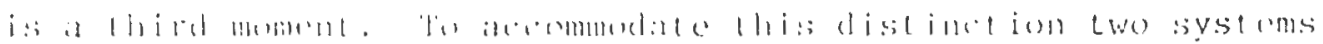

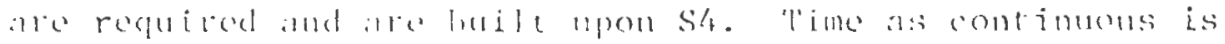

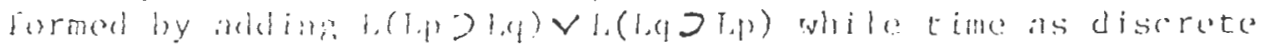

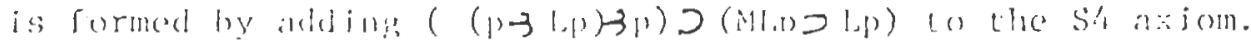


take the form of a contraciction. In tonse logics, as in the case of A.N. Prior, it secris tenable that senses of 'impossibjlity' conld have siphificance while nos havine the sencral form uf contradiction. This hovever anticipates the fores of the uponing 'Independent proof' that an impossble proposition entails any proposition.

Lewts and Lang,ford have argued that the paradexes not only do not tell against the system of strict inglication riving, expression

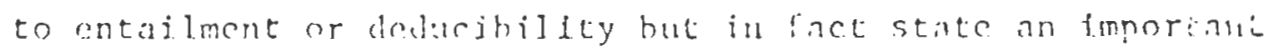
principle concemins, these concepts. The prouf procecds as follows. We trike any proposition wich fis of the form purp and assme the negation. Thjs sets us on our wy for the denial of pvap casily gives us p and $\sim p$. Of courac, the lesson to be learned is that if someone should contraljet or shor inconsistency then we should expect any proposition to follow.

The lesson beritins tiphs:

$\begin{array}{ll}1 & \cdots \sim r \\ 2 & r \\ 3 & \sim r \\ 4 & \Gamma \vee 9 \\ 5 & 1\end{array}$

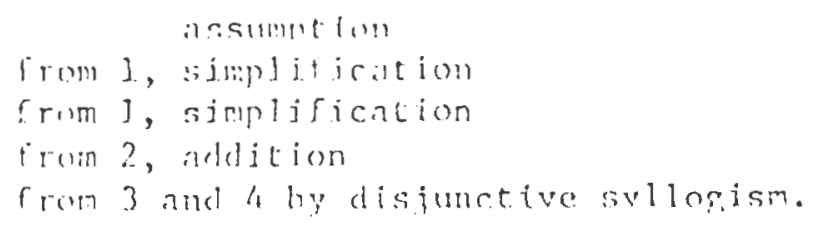

The proponents of this arsurent appral to the intuilive validieg of the component inforence moves. The following set of statements rives those rules for inspection.

A. Any confunction entails sach of itsi compuncts.

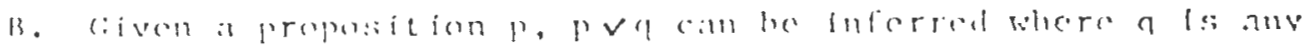

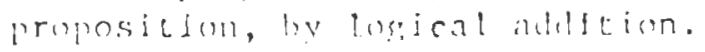

C. Irom the promises $\sim p$ airel pva one is cotitled to infer 7

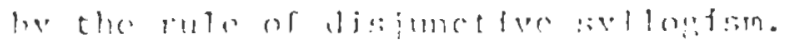


D. Implicit to this argument is also the transitivity of entaliment, that is $p$ implies $q$ and $q$ implies $r$, therefore, $p$ implies $r$.

In what follows, arsument will be given in bief for the rejection

of some of these rules and their success or failure likewise will be discussed.

Under $A$ we have the logical operation of conjunction which allows true premises to he conjoined and conversely the operation of simplification exemplificd by the inference made at steps 1 and 3 ahove. It has been argued by some that the premises of an argument should function together in entailing a conclusion. 26 The import of such a system would be that if two propositions A and $B$, given conjoined as $A \cdot B$ are said to entail some proposition $C$ then it does so in virtue of the joint force of both or a mutual functioning. $A \cdot B$ is not to be considered simply as $A$ is true and $B$ is true. In this form $A \cdot B$ would not entail $A$ because $A$ entails $A$, and $B$ would in this case be superfluous. T.J. Smiley has attempted to modify this version, by certain modifications, which ultimately remove the paradoxes; however, this results in an awkward system. Smilcy modifies the formal demand that the premises function together. 27 Smiley offers a definition of entailment in which the propositions entailed are contingent, likewise in this context the premises are contingent. He offers the following definition:28

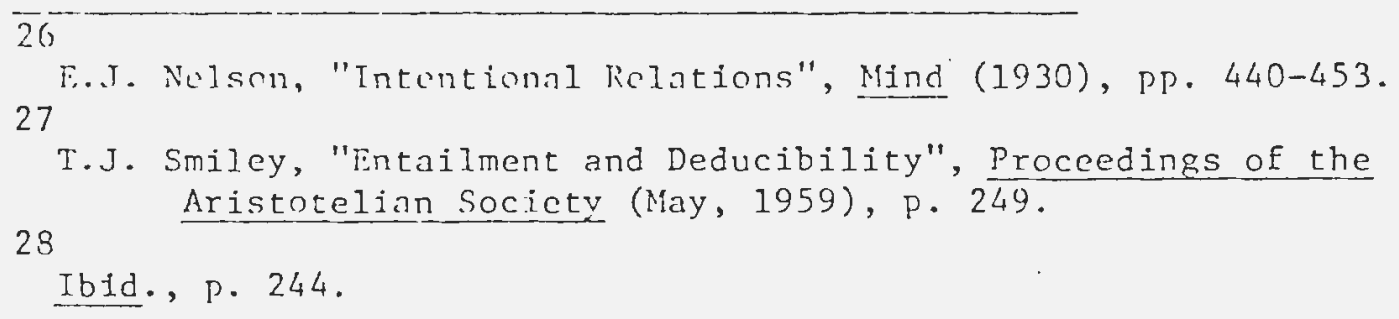




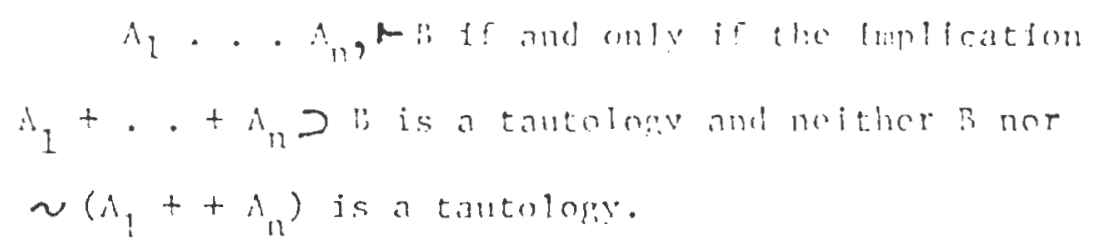

The system developed employing this deflnition for rntatlment a] lows $A$ - b t $A$ only when $A$ nd b aro colpatihle with nue another. This line of arrument which rejects internally inconststent promiscs does stop the 'paradoxes' ror on this view the impossible propesitgon of ine one sould he invald for any profe. There is however a severe difficulty when cutes, for, on this view pronf enploying recuctio an absurchm its impossible. Tn the same Ifshe however, we can cntertain Von vefuht's claim; "Tf one could not discriminate between nuposteions which are entailed and proposit Inns which are not entafled, by impossible propositions, enverse pronf could not be valdely condueted. For it is essential to such

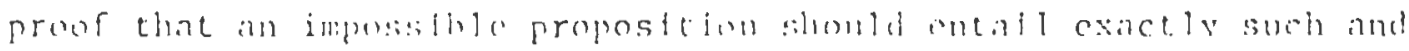

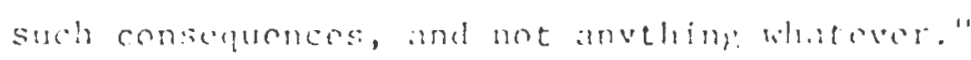

The vartance of interpretation for contradiclion and impossibility can take or different forms. For the case of von irisht the modai furfement of imposisibflity ts given to a pronosition which is inconsistent with a boly of bnowledpe. Thus, we camnt infer anything. from a contratiction, on his viow, except the denial of the

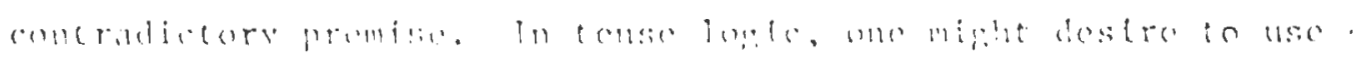
$\sqrt{19}$ 30 Ihil., r. 2h,

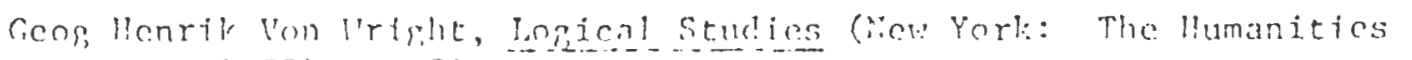
Prosis, 1957) r. I\%, 


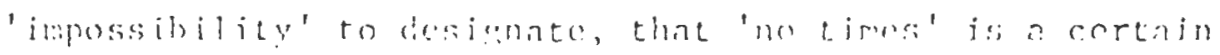
proposition true sithme the self samo proposition having tho form of a contrabiction. With Smiley, abose, the rontradictory premiso is simplv cacluded at the outset. be mav rote at this polnt then, that dopending on tho interpretation one may argue, that a contradictory premise implics cverything, as is the case

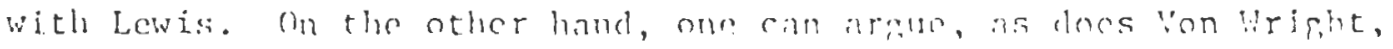
that only certain results can be inferpod from a contradiceory, anr?

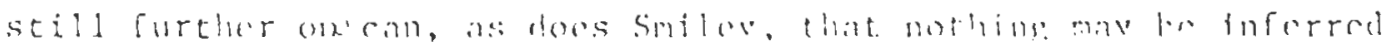
rrom a contrabielory.

Anderson and kelnap have put forth the most ponctrating critictsm of Jouis' independent pronf, that n contradiction chtajls

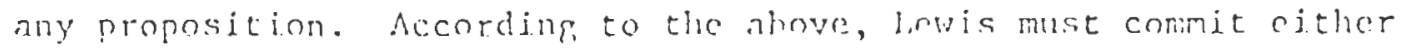

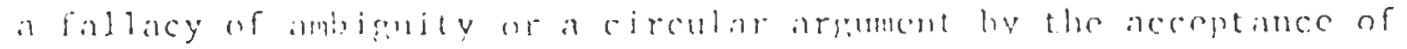
31

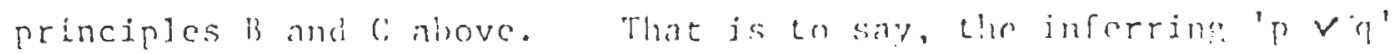

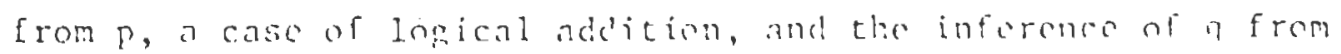

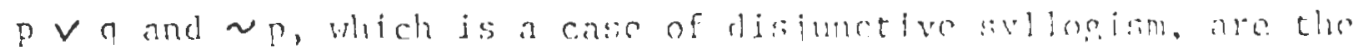
focal point of criticism.

The inference scinone of $A \vee B$ from $A$ is dependert on truth functional consjurations of ' $\checkmark$ ', in mbich the statement $A \checkmark$ is unicrstool ns;, cither $A$ is asscerted or $B$ is, and since $A$ is in

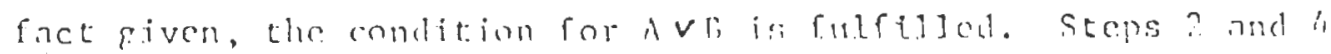

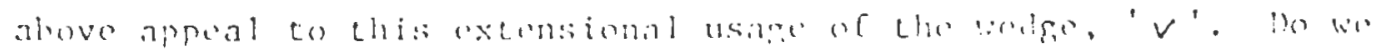
not in Enct, often use the wedse, transhated as 'or', in an intensional sense and fo this not presupposed for the nove to 5 ? This is the contention of Antorsm nut Polnop. That is to sav, in our Andersan and lielang, "Jintailnent", p. lor. 


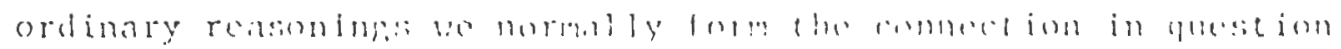
32

when there is sone relevance hetrorn the dis jumets.

The trablitinnally accepted rule of dis.jumetjun sylinaism, which in the two-valued propositional calculus, appears unquestionable, is rejected by the authors by the imposition of comlitions none too ohvious. It is apparent that a preliminarv account of the rule is usunlly enough to convince sonicone, that the rule is acechtoble. When given a chulec between two dis imuts, surh thit oither the first or the scoond is true, and following. upon this. piven that one is not the case, it scoms undentable that the reninining choice must be the case. This, however, is not the point of contention. What is of concern, is uhether the proposition 'follows from' the premiscs, in any lorically interestinr sonse, ocher than the extensional comblinn. What actually happens is not the rojection of ald instances of blsiunctive : tions that it fails to be an inference form. Ihe reloction of disjunctive syllogism $i_{\text {: }}$ in accors with the demand of fmposins rigid conditions for the Insical notion of 'vald illference'. The domand in question beinf, that ony conclusion inferred from promises must not he totally irrelevant; any valid inference must not comajt a fallacy of relevance. As for disiunctive syllogisw, the reatertus

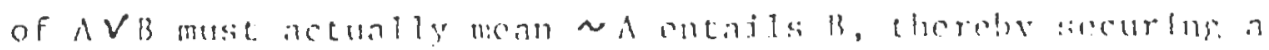

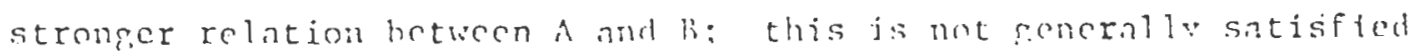
for lisjunctive syllog, is

32

Inide, p. 107. 


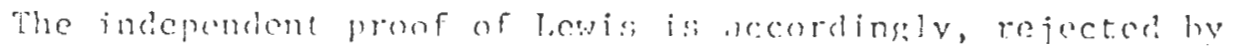
Anderson and Belmap. In the proor there is an ambetsity imaspuch as, $A V$ is of line 4 is produced by oxtonsional ficatures, while its subsequont was assmacs or rather needs the 'imensional

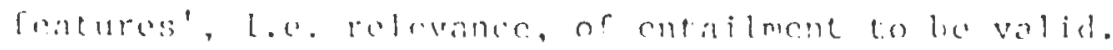

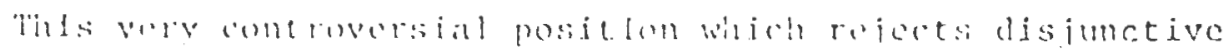
syllogism air a valld mode of inference is often comsidered ton hish n price to miy by many. Put if tho disiunctive syilogism is to be kejt, the above arsument must he answeres. Those who thubt the above argument lave done so by several mothos's. The most obvious rests on the concept of relevance. non midht insist, and rishtly so, that if the concent of relcuance is to form the basis of rujertion for such n lons accented princinle or inference thon there oubht to he a rigorons formutatom of such an elusive concept. That there is in fact such an adequate and formal cxprossion is to he ackmbledged. It will and he discussed here, put rather in upeoming seceions, inasmuch ats the roncept of relevance

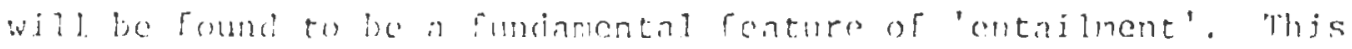
Will he discussod in the developmont of susten 'F'. (F for entaisment) of duideram and liolnap.

Another sfde to liw athack on the call for rolovance cited

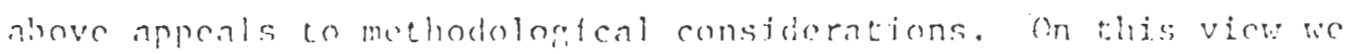

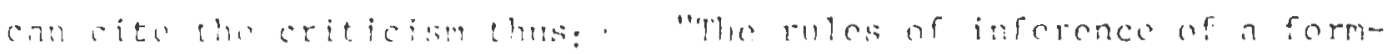
al system whose tinuroms (on thele intended interpretation) are 33 11) id. , Y. 10:i 


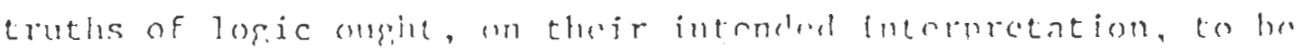
$3 !$

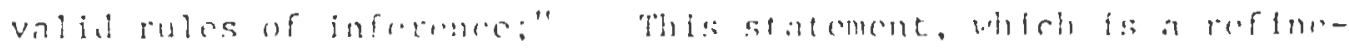
rient of nue aspect of Anderson and Bejuap's crtejcism or dis-

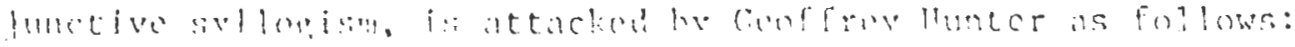

"I regard the rule of inference of lis, unt as solucthing that on its intencled interpretation has to be a valid ruls of inference, lut mercly ns a rulc for seneratins. 5n rmillas that, on their intended interpretation, express truths of logic. il dows mot mattor for

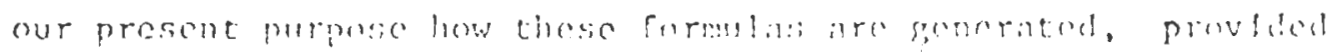
that they are al 1 gonerated (and that nothing else is)." 35 This

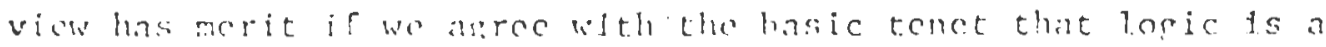

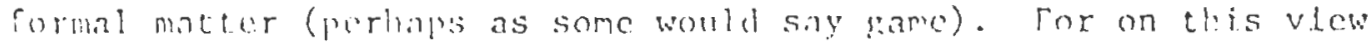
the call for relevance j.s irgclevant, in so far as a rule of inference loes not have lo be a 'valid' rule of inference. This, however, has the appoarance of a red herring. To estahlish melhod:i of Fencrating formulas in accordance with the concopt of lostcat consequence, to rif ablish 'truths of logis' is very noble and in-

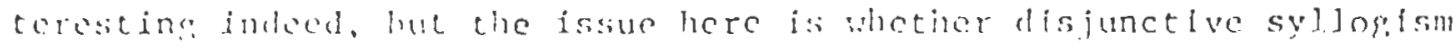
isi an arepulable rule, because of certing combitinas.

In al? faimess, we should likewise obscrve that Arcicrson and Belmap have developed a system whell excludes dis junctive syllopism and Iikerdac molus guncus. The systom callod AB ls somantically complete, consistcat and decidable. Not meaning to go too far afield 34 3.5

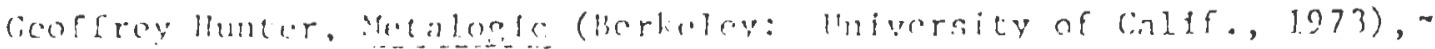
[?. $1: 5$

Ibid., ?. I?h 
ve shall note in massing that the systent is construted criploying:

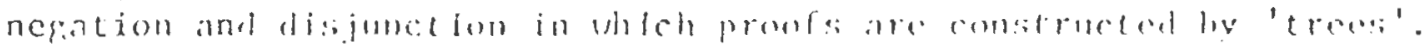
A formula or string of formulas of a linanch oncis in either the probution of an axiom, in which case the formula is a theorem.

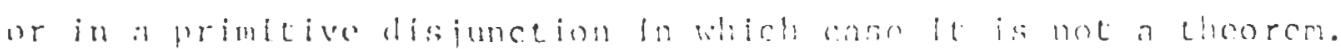
If a fallacy of ambleuity becwecu the intensional and cxtensional uses of the worle is sought to be nuojded by an alternate sense of 'valid form of inference', thon accoteling to Anderson and Belnap a circulir argument may resulte The derand eiven at the

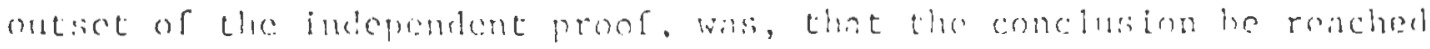
by some 'valid mole of inference'. If in the independent proof 'strict validity' is the eriterion for valiol form of inference then

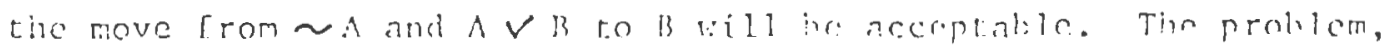
however, with 'striet valjdity', whin wold silv the criterion for valid inference ls that it is necossary, that cither the ronclusion be true or the prenises false, that the arsument employing dfsjunctive sylloglsm would be mmecossary. On this vien $\Lambda$ - $\sim$ vould validate an inference to B, insofor as $A$ o $\sim$ must ho falso. This however, renders the independent proof superfluous. If the indepensiont

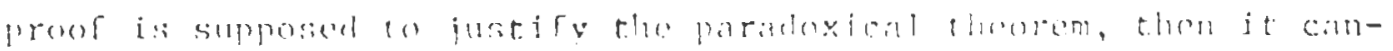
not appeal to strict inplication wich pives the theorem, in the 37

rirst niar.

lic may now turn our discussion to the finnl principlo of in-

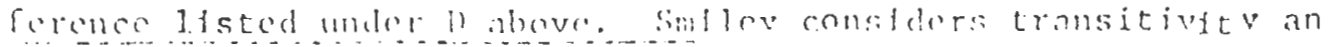
$3 i$

37 thide, pr, 127-134.

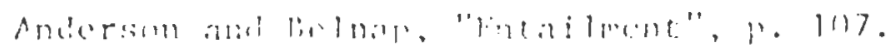


essential factor of a paradox-free system of entailment. He also suggests that transitivity may be fundamental factor for satisfying the call for a 'connection of meanings' (or relevance) in entailment. That is to say, the limiting or restricting of transitivity will count in favor of or correspond to the idea of a connexion of meanings. 38

Smiley offers the following definition of entailment: $A, . ., A \vdash B$ if and only if the implication $A_{1}+\ldots+A_{n} \supset B$ is a substitution instance of a tautology $\mathrm{A}_{i}^{\prime}+\ldots+\mathrm{A}^{\prime} \supset \mathrm{B}^{\prime}$, such that neither $F \mathrm{~B}^{\prime}$ nor $\operatorname{par}\left(A_{1}^{\prime}+\ldots+A_{n}^{\prime}\right) \cdot 39$

Transitivity in the above view fails in the attempt to establish the middle term between $A \operatorname{dm} A r(A \vee \mathrm{B}) \quad \& \sim \mathrm{A}$, along with $(A \vee B) \& \sim A \vdash B$. This happens because of the principle of inference which would validate the above, excludes the formation of the middle term. The actual principle would give only, $A \& C F(A \vee B) \& C$ and $(A \vee \dot{B}) \& \sim A \sim B$, which have no middle term in common.

In the beginning of this section it was mentioned that there were several renderings for entailment. Depending on one's position one might believe that strict implication and entailment are the same; it has been the aim of previous discussion to cast doubt on this identification. A telling feature of this doubt enters with the 'paradoxes'. $\because \cdots \cdot \cdots \cdots \cdot, \cdots, \cdots, \cdots$

38 Silley, p. 237.
39 … . . 2
Ibia. , p. 240.
Ibid. , p. 241:




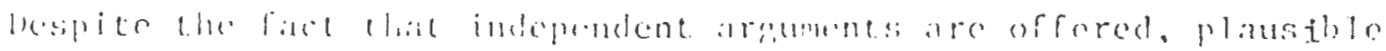

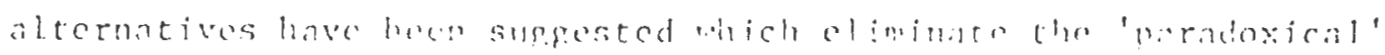
grinciples. As con he seon, theso altermatires, as in the cases

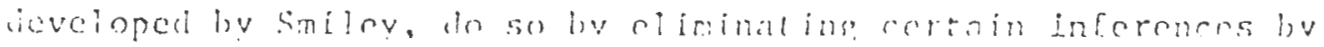

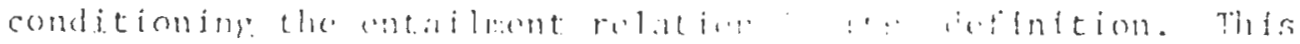

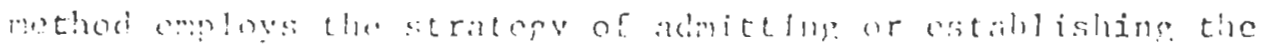

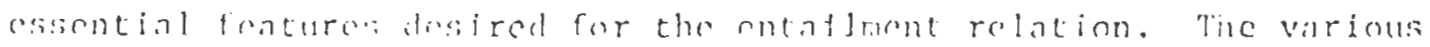

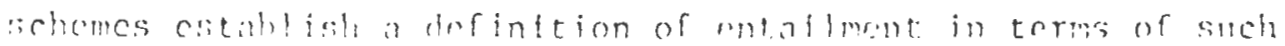

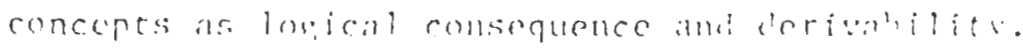

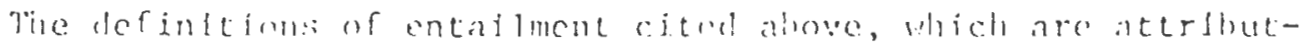

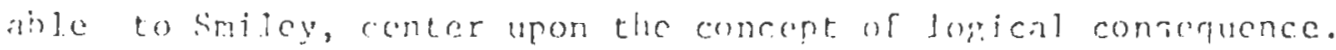
In such an apposch the conelitions are solectes in acenriance

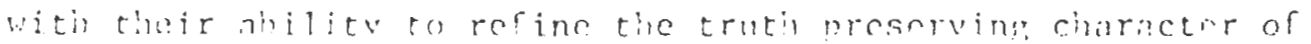
1,1

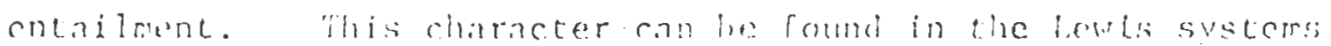

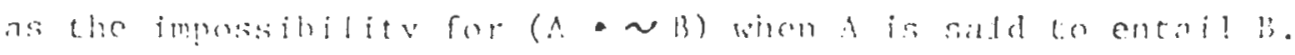

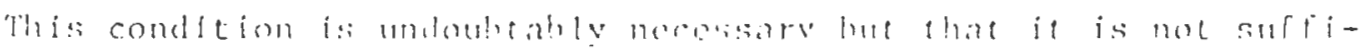

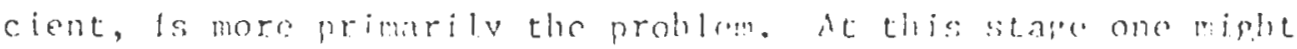

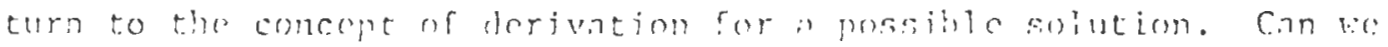

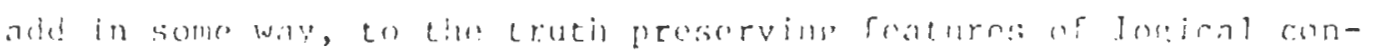
sonquner derlvational features to arrive al a sal jafving arcount of

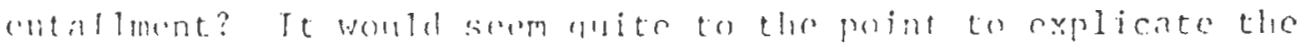

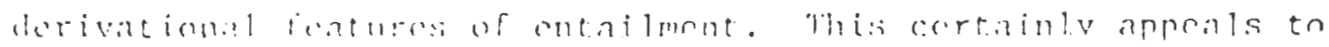

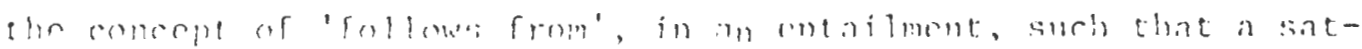

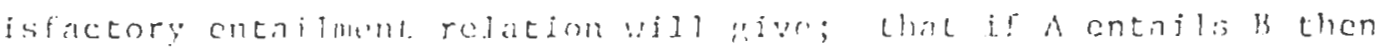
i, ] Hil, , r. ? ? . 


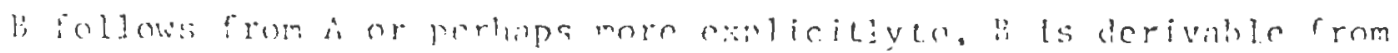

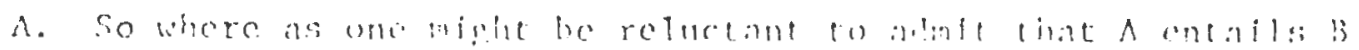

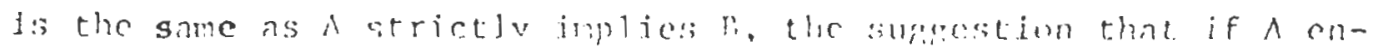

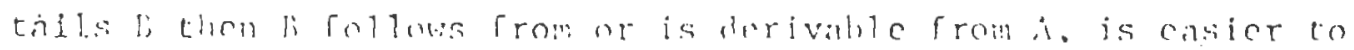

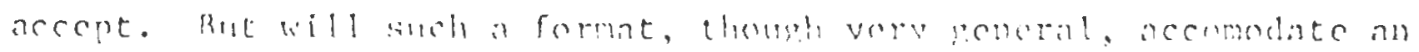
accentable cxplication of relevence, if the concept of relevance is insisted upon?

The criticism of asjunctive syllonim am lerical adhition as

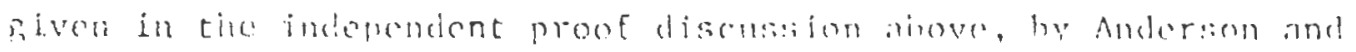

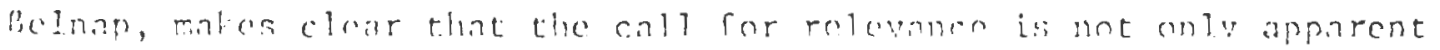
in lisht of the 'parar?oxes', but likewise oceurs as prounds for

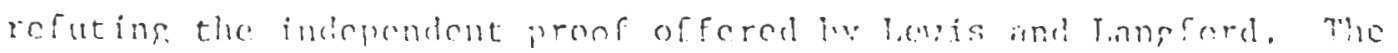
answer then is perhaps, that to property explicate the comerpt of

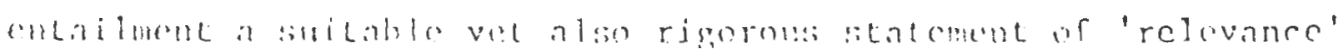
ralse he integrated Into the borivational syntas. put hob would such a method compare to those used he similov abuve? The rirst pojut to he ohservel is that although Smilev recomizes the necd to satEsty the demand ing a 'connection of meminges' ar 'relevance' he

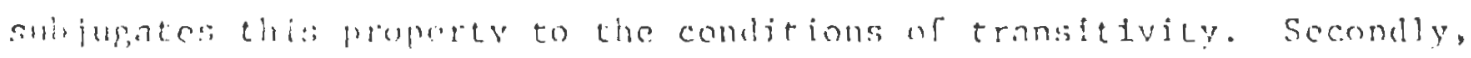

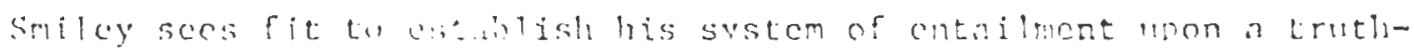

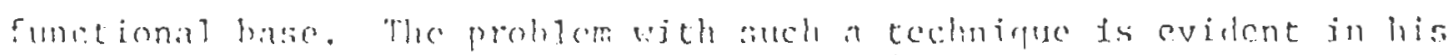

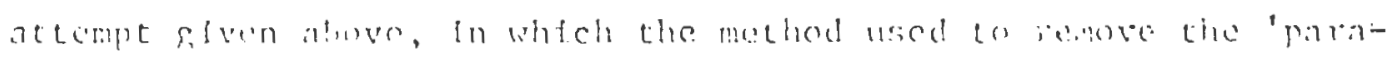

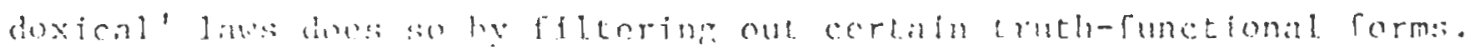

That the subsequent systems are arkaril is umoniable, Yot the basic iden of hulldils. the non-extmalumal modal lostc nu an exten-

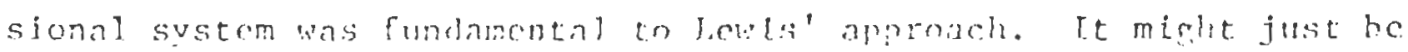


the case that such a rothor? vil] nue leave rous for an mirguate.

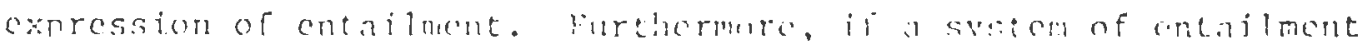

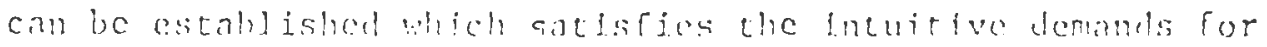
relevance and the necessfty of lonical comseruence. and yet is distince from the sititon of serict imblication then we should

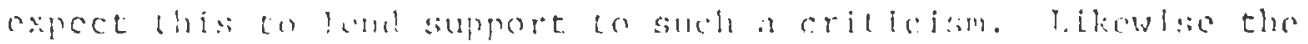
positgon that the 'paraloxes' are but rere freaks is similarly weakened. If it cin he shown that lhe 'paradoxical' prineiples are

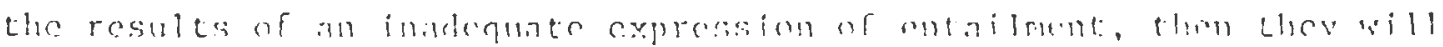

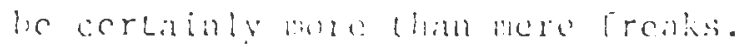


CMAPTER IV

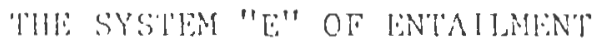

1. The mevelopment of system E:

The system to be presented in whit follows is a system of

"entailment," which solves the problem of the paradoxes of implication. It does so in virtue of a rigorous and specialized sense of implication. The rirst point to be considered is thit, whoreas the horseshoe symbol was used to represent material implication and the rishhook for strict impication, the arrow" $\rightarrow$ "will be used to represent lie logical relation of entaliment. Futher, it will be argued that the relation of entailment gives a proper statement of the fundamental philosophical problem of implication. In the course of such a statement, the paradoxical features associated with material and strict implication as siven by certain theorms will be found to be unprovable and in fact, rationil. prounds for rejecting both material and strict implication as kinds of implication at all. lt is the opinion of this writer, however, that this does not render the systems previousty discussed exercises in lutility; on the contraty, what is moanc is that it is perhaps simply a mistake to call such relations implication from a philosophical point of view.

The system "li" for entailment was formulited by Alan Ross Amberson and Nubl b. BoLnap. Tn this system, it is argued that there ar two essential ingredients for a proper system of entailment. One

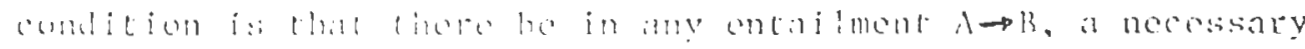




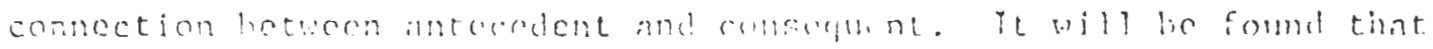
the develnment of mocosity as usol in lhe sustem of lingls and hangeford discussed carljer is suffictent. On the other hand, there

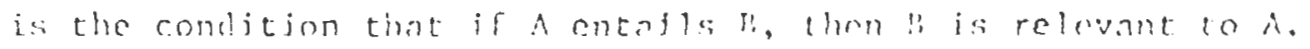
At stake here is the philosmpiral impurtanes of logical

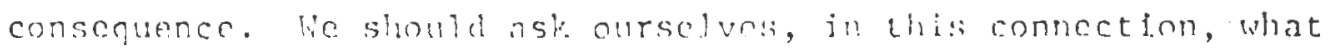
fontures we require to employ this concept propery, so as to rive proper cxpression to the above montiomed comblitions, while at the same time elininatins the undesirable features in cortain altermative syestuns. The ronst olvious result yichis an interprotation Cor such key concepls as "Enllows from", "implies", "is deducfble fron", "thereforc", etc., in our lorical locutlons about our deductive apiaratus. The formula formed $A \supset(B>A)$, wich can he interpreted If $A$ is true, then $A$ follows from any arlitearv $B$, is accentable in the system of material impleation; it is not aceeptable in tios

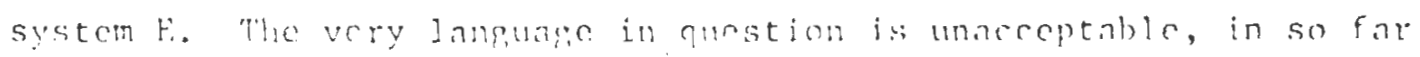
as a true $A$ does not follow from any arbjtrary contingent $B$ fn any proper sense of "rollow from".

In what follows, the system l: will be presented with attontion cispefally on the development of the dediet ive apparatus. In the course of this development, ripornus expression will be riven to both necessity and relevance.

\section{Meduce ive Mechos!}

The basic method for proof procciure will be a variant of

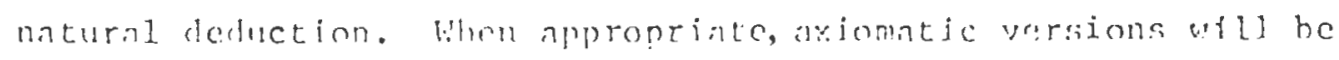

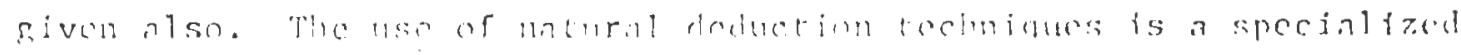




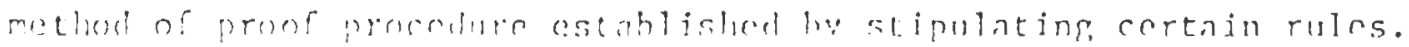
since the pareicular broblem here comerens the jmilleational reatures,

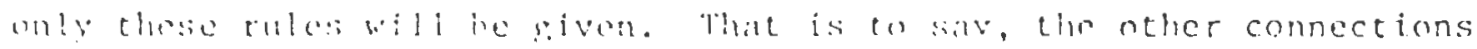
will he mited, i.e., the conjunction and disfunction as fell as the neration sisn. Both hractets and "ets" will he used in the formation of formulas. Nots are to ho entererl by convention [rom the left.

The following, rules are to bre used:

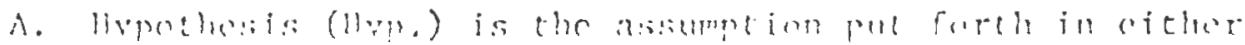

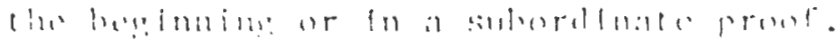

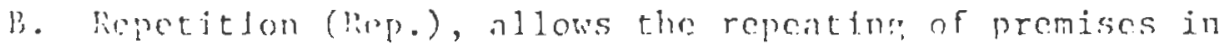
t!ic same proot.

C. Teiteration (Reit.), allous the repeating of premists into subprouls.

1). Fintilment Introduction $(\rightarrow J)$, allows the assertion or

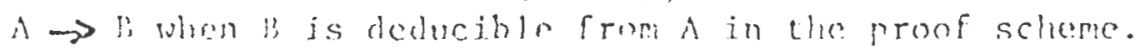

F. Eninidment litimination $(\rightarrow F)$, allovs the inference of

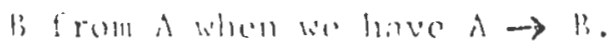

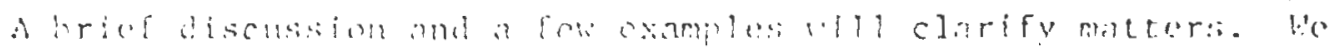
ma first observe lla very simple prour for the law of identity.

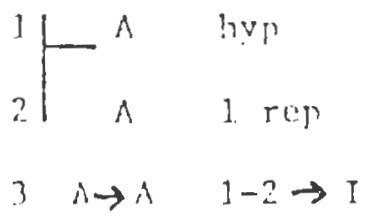

This simple proof exemplfies the hasie use of hypneliesis, rep-

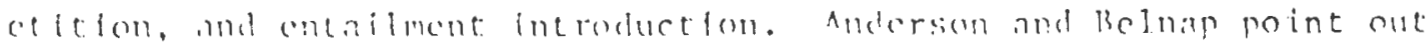
$\because ?^{+\cdots}$

Andersion and belnal!. "Bntailment", p. Rn-8\%. 


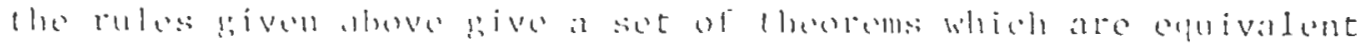

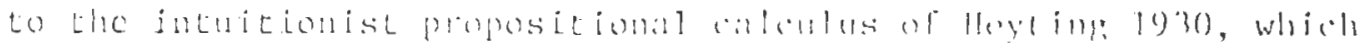
consists of the following two axioms with entailnent elimination.

$$
\begin{aligned}
& \text { III } A \rightarrow B \rightarrow A \\
& \text { II: } \quad(\Lambda \rightarrow \cdot B \rightarrow \text { ( }) \quad \cdot \lambda \rightarrow B \rightarrow \cdot \Lambda \rightarrow C
\end{aligned}
$$

111 is the familiar paradox and is proved by the above five rules as follow:

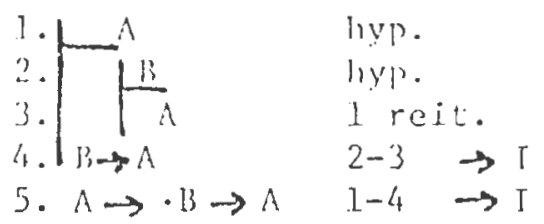

Ankerson and Belnap point out that this is not an instance of entailment, "For if $\Lambda$ is contingent, then $A \rightarrow \cdot B \rightarrow \Lambda$ says that an entaibment $B \rightarrow A$ follows from or is dedeseiblo from a contingent proposition - in defiance of the condition that formal considerations alone valjolate valid inferences." ${ }^{43}$ lisisentially, the above formula in no way gives any acceptable form of implication. The fact that one utcering such a formula will not produce a ralsehood does not justify the use of "implies" in this formula nor any acceptable sense of deducibility of $A$ from $B$.

Anderson and lielmap at this point atempto modify the rules so that formulas like the above mentioned will be onited. The missins element is necessity. That is, the mulification mut guarantec that Ingical truths shitl be necessary and not continuent, "These considerations sugsest that wo should he al lowed to import into a 43 Tbicl., r. 86. 
dedection (i.e. into at subproof by reiforation) only propositions

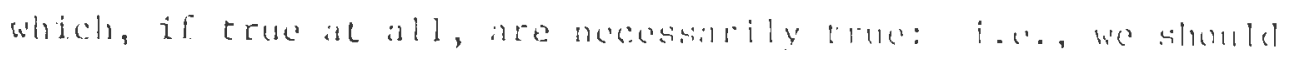
reiterate only entailments. 144

The system so nodified, callod by the authors $54 \mathrm{I}, *$ is

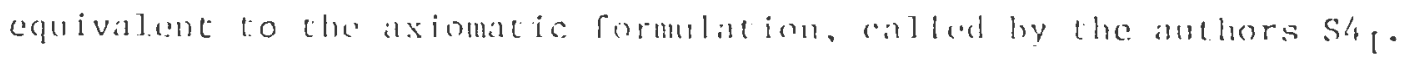
These axioms form the implicat ional reagment of lowis's $5 t_{4} 45$

$$
\begin{aligned}
& S 4,1 \quad \wedge \rightarrow \wedge \\
& S / 41^{2} \quad(\Lambda \rightarrow \cdot B \rightarrow(:) \rightarrow \cdot \Lambda \rightarrow B \rightarrow \cdot \Lambda \rightarrow: \\
& \therefore 4 \mathrm{I}^{3} \wedge \rightarrow B \rightarrow \cdot C \rightarrow \cdot \Lambda \rightarrow B
\end{aligned}
$$

The systom so modified, however, has its own prohlems as was discussed an previuss chaptors. The problem being that nuy necessarily true proposicion is entailod by any jrrelevant proposition. $B \rightarrow \cdot \lambda \rightarrow \lambda$ is derived from the above by axion s4, and $\$ 4,9$. An alfernate derivation from the modified rules gives:

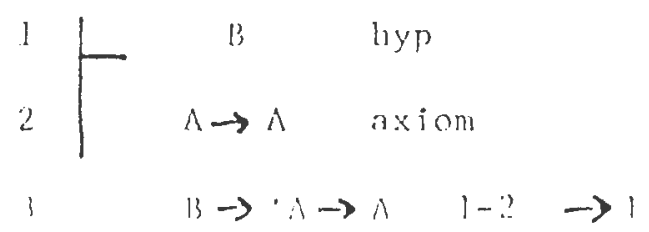

In the example, the dativation is valid by the rules given. It is unconvincing however, that $\Lambda \rightarrow \wedge$ follows, in any interesting sonse, from B. Andersom and Belnap suphest that the above proof fails to 4

Ibid. . P. 87
$11, \mathrm{idl}, \mathrm{P} .88$ 
take seriously the worl "from" in proof from hypatheses." The

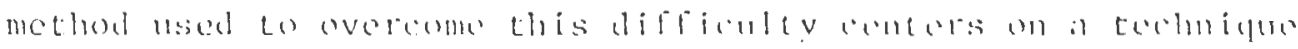
wich would allow the reeping track of premises and their usage, "what is wanted is a system for which there is a provable deduction thoorem, to the offect that there exists a poof of $B$ from the hypothesis $\Lambda$ if and only if $\Lambda \rightarrow$ B is provable."

A suhscripting procedure is used to keop track of the premises and to mark their entry into usage. "phe relevance indices are thereby entered and discharged much the same as proots and subproofs use the " $\rightarrow$ 1" rule. The rules which [ollows, insure that if $A \rightarrow B$ then $\wedge$ is relevant to $B .^{47}$

1. Fach hypothesis is given a distinct mumerical subscript $k$, where $k$ is different han any other previous $h(k)$

2. From $A_{a}$ and $(A \rightarrow B)$ b to infer $B$ a $\because b$

3. From a proof of $B$ a from hypothosis $A(k)$, where $k$ is in $\therefore$, in infar $A \rightarrow B$ a $-(k \cdot)$

4. Roiteration and repetition retain subscripts.

The following proof of transitivity is offered as cxample:

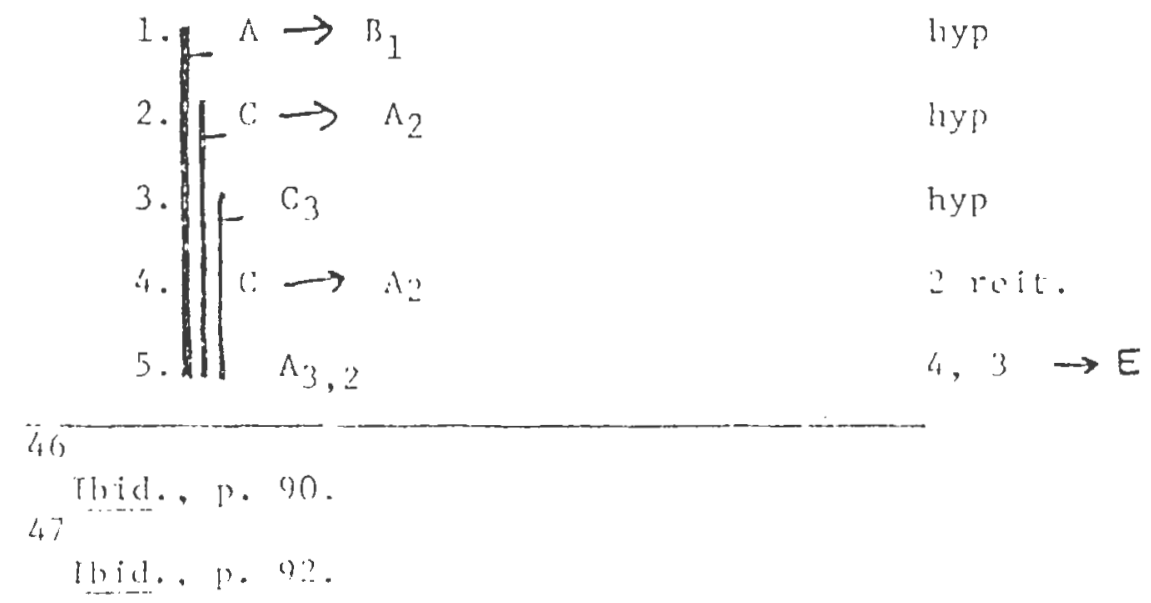




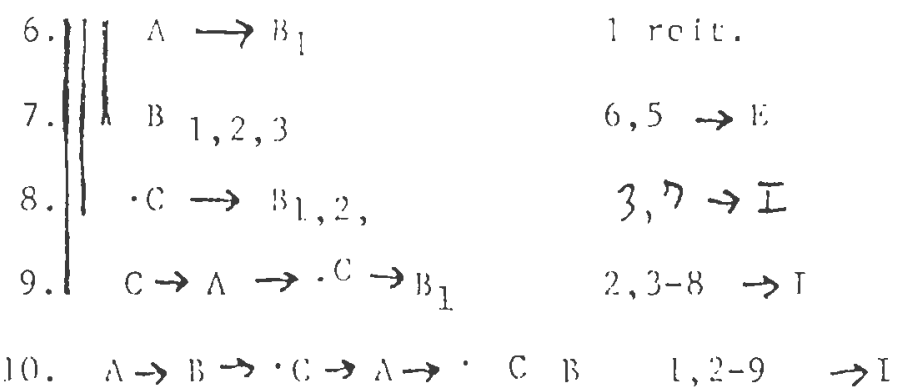

An axiomatic councerpart was developed by $\Lambda 10$ \%o Church and called "weak positive implicational propositional calculus." The arinms are: 48

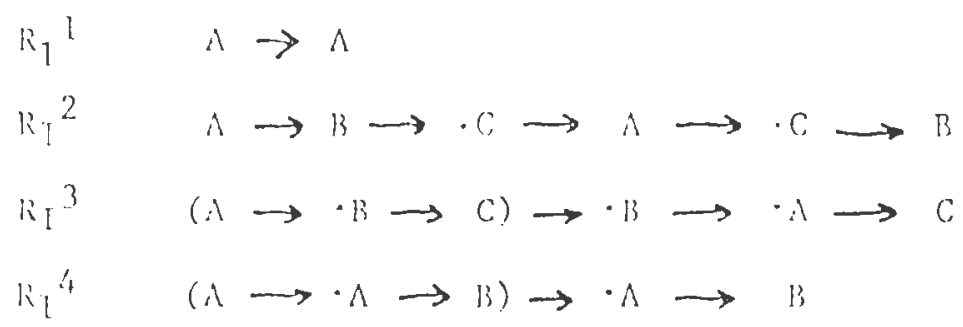

Anderson and Belnap call this system $R_{L}$, while the natural deduction version is referred to as $\mathrm{RI}^{*}$. The $R$, of course, is meant to signiSy relevance.

In either case, the condition of relevince is given formal

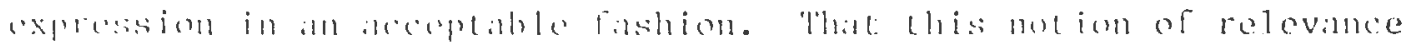
is philosophically acoptable will be considered in what follows. The systom $k_{l}^{*}$ does have its prohloms such that it is not properly an cntailment system. For in this form a very obvious modal fallacy occurs. The s systems of modal loric discussed in earlier chapters deline necossity in torms of logical truth: thit is, moossary 48 Ihid., p. 90. 
truths are talutologrial truths. Tho systom $k_{1}{ }^{*}$ igmores such ronsideration of nocosity hy the following lhentem.

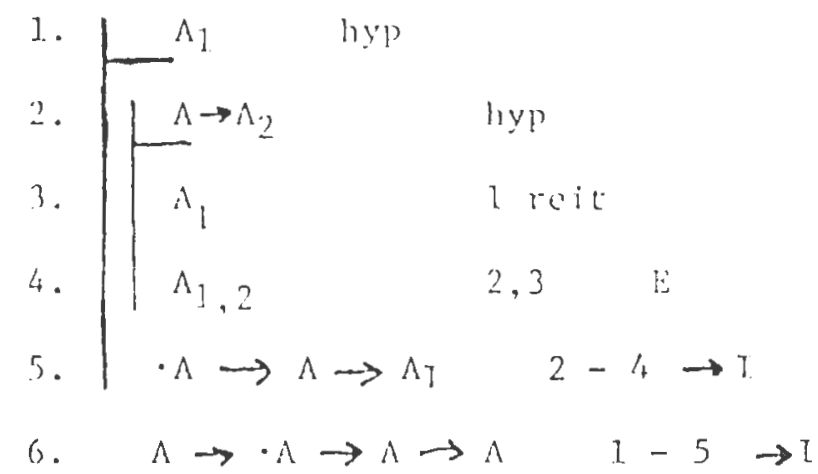

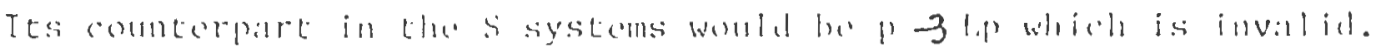
$\cdot \Lambda \rightarrow \Lambda \rightarrow \Lambda$ is given by Anderson and Bolnap as the definition of mensity. The meming is that is A is necessiry, then A follows from in logical truth. The authors are quick to point out that from a formal point of viow, the definition of necossity as $\mathrm{N} \Lambda=\cdot \Lambda \rightarrow \Lambda \rightarrow \Lambda$ Is equivalent to those in the systems of towis and Iangfourd. it The most obvious results suggests that the condition of nocessity be combined with the relevance conditum. 'This is precisely tho mechod of arriving, at the system k.

The sytem is whlained by combining the restriction for reiteration of $\$ \mathrm{ST}^{*}$ and the subseripting technique of $\mathrm{K}_{\mathrm{T}}$ " The rulas so moliliod are: 50

1. Hyp. A step may be introduced as the hypothesis of a new subproff, and each new hypothesis receives a unit class $\{r\}$ of numerical subseripts, whore $k$ is new.

2. Rep. $A_{i}$ may be repeated, retaining the relevance indices

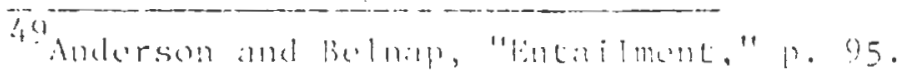
50 lhi,l., p. 93. 
3. Leje. $(\Lambda \rightarrow$ in) a may be roiteraind, rotainine n.

4. $\rightarrow$ F. From di and $A \rightarrow$ Pb, to infer babl.

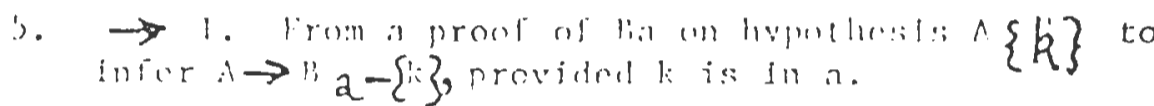

The followeng proofs are stuen for inspertion.

Specialjzod Assertion

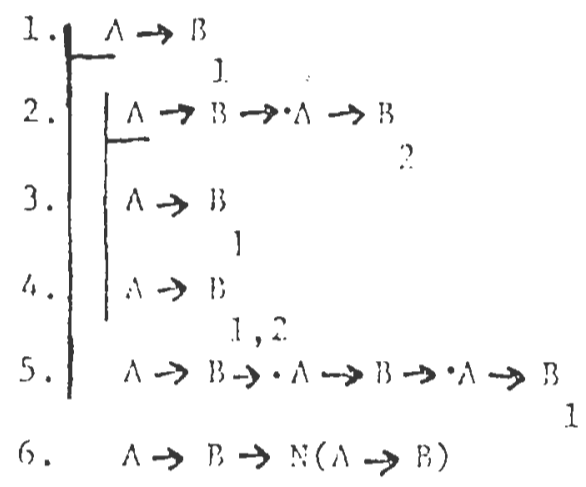

hyn.

hyp.

1 reit.

$2,3 \rightarrow R$

$2-4 \rightarrow I$

$1-5 \rightarrow \mathrm{I}$

Transigivity (surfixins)

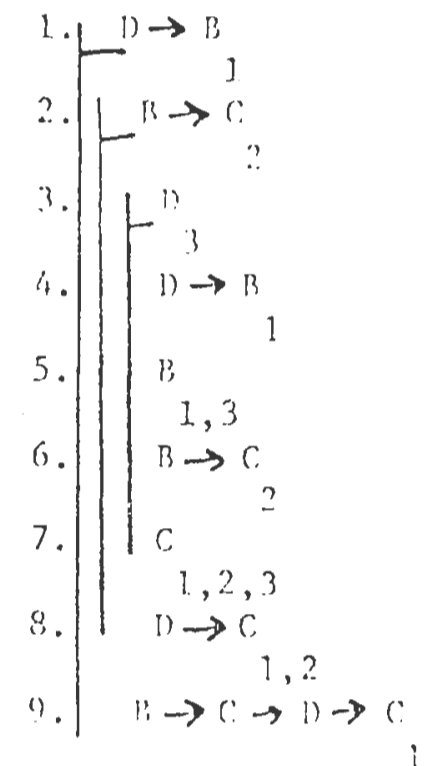

$h y$.

ive.

nyp.

1. rett.

$3,4 \rightarrow F$

2 reit.

$5,6 \rightarrow E$

$3-7 \rightarrow I$

$2-8 \rightarrow 1$

10. $\quad \mathrm{n} \rightarrow \mathrm{B} \rightarrow \mathrm{I} \rightarrow \mathrm{C} \rightarrow \mathrm{D}) \rightarrow \mathrm{C}$

$1-9 \rightarrow I$ 


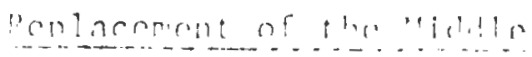
3.
hun.
lin.
$n n$.
1 roit.
$1,3 \rightarrow r$
? roit.
r. . . $\rightarrow$ r:
$3.7 \rightarrow 1$
$?-9 \rightarrow T$
10. $\operatorname{Lin} \rightarrow n \rightarrow$
hive.
inn.

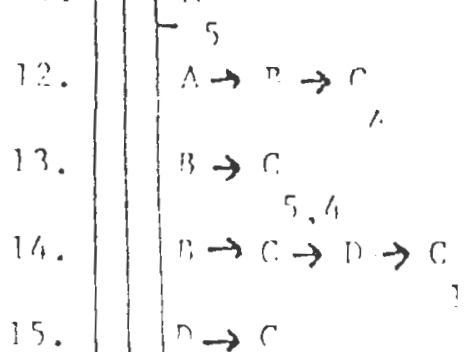
in reit.
$11,1 ? \rightarrow r$
9. risit,
$13.1 \% \rightarrow$
$11-15 \rightarrow T$

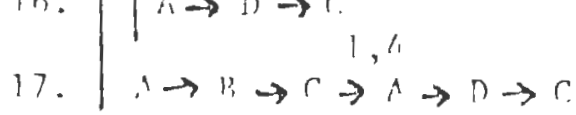
$10 .-16 \rightarrow 1$

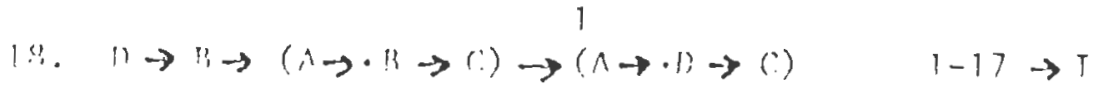




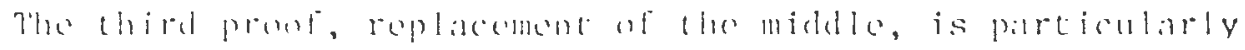

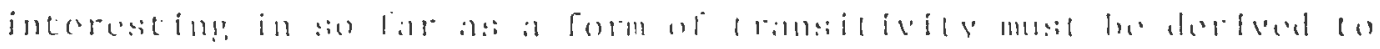
reach the conclusion in question. Tt is to be observed in fact, that the proof for transitivity ass given in the second proof forms the first nine steps of the third prowt The subseript of che first hypothesis is preserved through to the aldition of hypolheses four and live white the second and third hypotheses

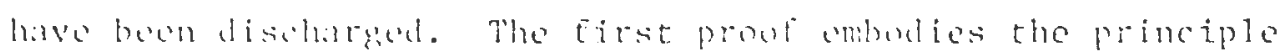

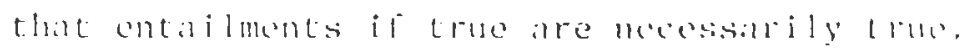

An axiomatic counterpart exists with the [ollowing axiom schema: $: 51$

Eutailment.

P. $1 \wedge \rightarrow \wedge \rightarrow P \rightarrow P$

I. . $\quad A \rightarrow B \rightarrow \cdot R \rightarrow C \rightarrow A \rightarrow C$

P. ? $(A \rightarrow \cdot A \rightarrow R) \rightarrow \cdot A \rightarrow B$

Conjuntions.

$F . / \quad(A \wedge B) \rightarrow \Lambda$

F.S $\left(\wedge \wedge \Gamma_{1}\right) \rightarrow R$

R.6 $(A \rightarrow B) \wedge(A \rightarrow C) \rightarrow . A \rightarrow\left(\Gamma \wedge C_{0}\right)$

$\because \because 7 \wedge \wedge \rightarrow N(A \wedge B) \quad[\because A=$ if $(A \rightarrow A) \rightarrow A]$

1) $i$ i jumet $i$ un.

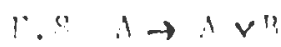

$r .1) \quad r \rightarrow \ln B$

$\because .10(a \rightarrow(n) \wedge(\mathrm{B} \rightarrow \mathrm{r}) \rightarrow(\Lambda \vee r) \rightarrow r$

F.L. $\wedge \wedge(B \vee C) \rightarrow(A \wedge B) \vee C$

51

Alan Ross Anderson, "Some Open Problems Concerning the System F of Entailment", Acta Philosophica Fennica, FASC. XVI (1963), p. 14 . 
Negation

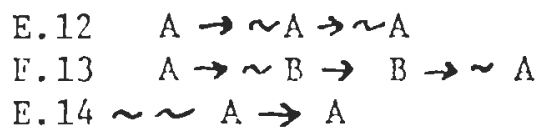

The above (preceilng). fourteen axions give a version with the truth functional connectives included. The rules of modus ponens and adjunction are emplcyed in this version.

2. Concluding remarks on the system E.

The system $\mathrm{E}$ of Anderson and Belnap is designed to explicate the concept of relevance while securing recessity in inference. The authors thereby reject material and strict implication as entallment calcull. The authols have thus attempted to give the conditions for the assertion of $\Lambda \rightarrow B$ where the formula is read 'A "entails" B'. A motivating feature ts suggested by the following statement. 52

The implication $P \supset q$ can be asserted, if and only if we possess a construction $r$, which, jolned to any construction proving p (supposing that the latter be effected), would automatically effect a construction proving $q$. In other words, a proof of $p$, together with $r$, would form a proof of $q$. (Heyting)!

Now, If "the implication of p $\supset$ q can be asserted", means what heyting says, then the arrow cf entallment answer exactly to the notion of "would autamatically cffect a constructicn of", whereby "answering exactly" we mean that

$$
A \supset \mathrm{B}=\operatorname{de} \cdot(\exists r)[\mathrm{r}(\mathrm{r} A \rightarrow B)] \text {. }
$$


The above statement does give an intultively acceptable statement of what is at stake in the development of the entaijment relation. As is seen by the preceeding matcrial a proper concept of relevance was required. For explication of the concept of "relevance" ce "conncetion of meaning" the following two conditiong fustify an affirmative response, for $E$, to the question, "Loes the formal system establish relevance between antecedent and consequent in an implication?"

1. The subscripting technique expresses that for A to be relevant to $\mathrm{B}$ it must be possible to use $A$ in a deduction of $B$ from $A$.

2. If $A \rightarrow B$ is provable in $E$ then $A$ and $B$ share $a$ variable. 5.3

The first condtion is both necessary and suffictent, whlle the second condition is necessary. The second condition is Froved by the following matrices: every ariom takes a designated $(+)$ value for all. assignments to its varlables and the rules of $I$ preserved this property. If $A \rightarrow P$ is such that $A$ and $B$ share no varlable, then there is an undesignated value assignment to $A \rightarrow B$. For example, assign the value th to the variables of $A$ while $B$ takes the value $t_{2}$, then $A$ will be $\pm_{1}$ and $B$ wll be $\pm_{2}$. However, $\pm I \rightarrow \pm 2$ takes the undesignated value -3 . Hence, if $A \rightarrow B$ then $A$ and $B$ share a variable. 54

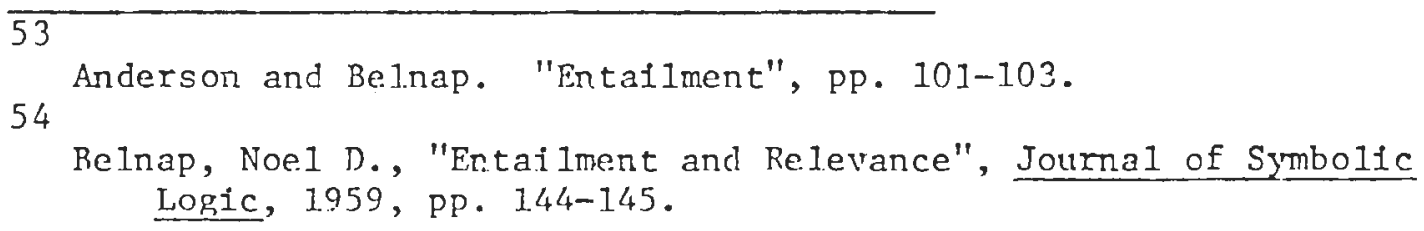




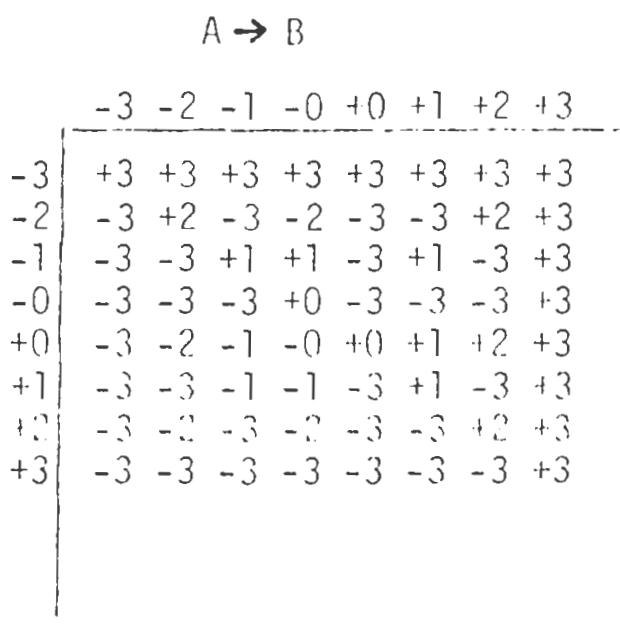

\begin{tabular}{l|l|l|l} 
& $\Lambda$ & $N \Lambda$ & $M n$ \\
& & & \\
-3 & +3 & -3 & -3 \\
-2 & +2 & -2 & -2 \\
-1 & +1 & -1 & -1 \\
-0 & +0 & -0 & -0 \\
+0 & -0 & +0 & +0 \\
+1 & -1 & +1 & +1 \\
.$+ ?$ & -2 & +2 & +2 \\
+3 & -3 & +3 & +3
\end{tabular}

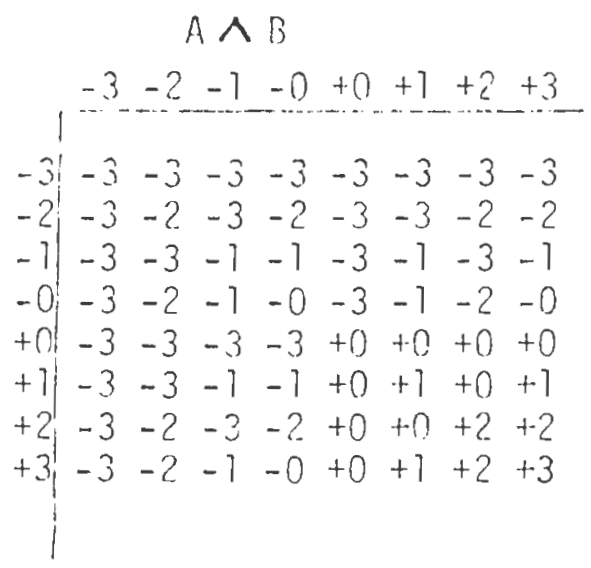

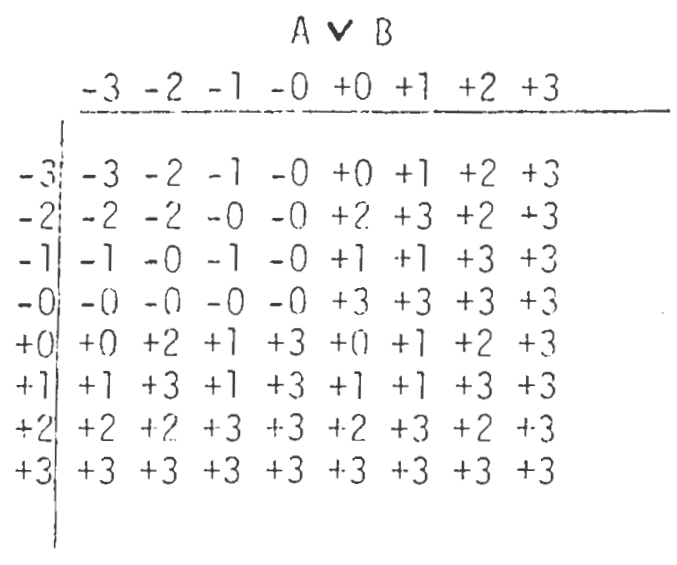

Designated values $+0,+1,+2,+3$. 
The system $E$ of Anderson and Belnap has been received favorably among contemporary logicians. Most literature on the system shows earnest attempts to find applications for the results obtained. Some critics do however exist. The nature of the criticisms requires two avenues of approach. First there is concern over the omission of disjunctive syllogism. Secondly, there has been concern over the validity of the relevance condition. The criticisms over the rejection of disjunctive syllogism are sufficiently covered in Chapter III.

The relevance condition is discussed by Donald J. Hockney in an article entitled "A Vindication of System E." He gives the following form of the relevance condition:

"If $A$ and $B$ have no variables in common, 'A entails $\mathrm{b}$ ' is rejected as a theorem of the system." 55

Critics have attempted to reject this postulate by insisting - that the postulate cannot accommodate all entailments. Consider the following case:

"If something is blue, then something is colored."56 This is offered as a case which cannot be handled by the above postulate. Hockney points cut however, that the relevance postulate is given for a propositional $\operatorname{logic}$, and consequently is not

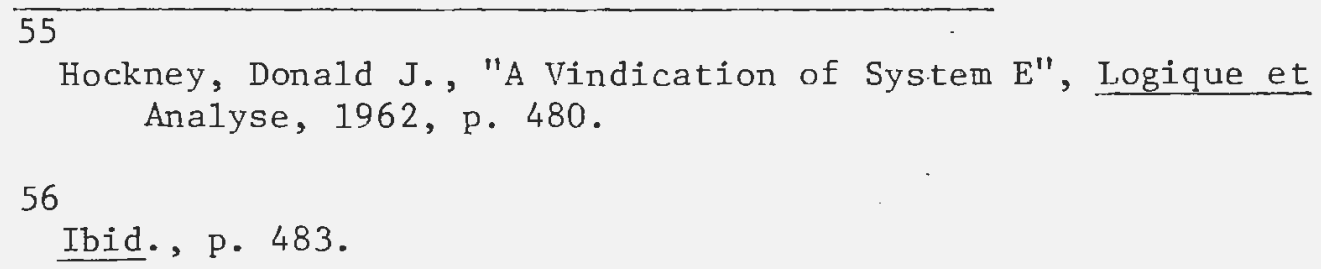


designed to deal with analyzed propositions. There is no reason why a reconstruct on of such examples as above cannot be performed prior to the application of the relevance postulate. In fact, to properly extend the use of the entailment sign for predicates logic would seem to necessitate an entire system of definitions to introduce non-logical descriptions. This general method is dealt with by Carnap in Meaning and Necessity.

Robert K. Meyer in "Entailment" has argued that the system E of Anderson and Belnap is fundamentally correct. More particularly, it is the claim that relevance between antecedent and consequent is needed for entailment which is correct.

Meyer is especially impressed with the development of 'relevant implication,' (see previous chapter). To accent what the author sees to be the more important issues of relevance he develops a logic of irrelevance.' This mock-serious system allows any arbitrary ' $\mathrm{p}$ ' to be a theorem. In this system the author points out that all our "logical intuitions" break down. Analogously, our locial intuitions break down over the inference of an irrelevant p from any contradiction whatsoever. The system of irrelevance produces inconsistency and so is apparently useless but systems which incorporate the paradoxes although they do not produce inconsistency are not harmless. 57

Underlining the problem is the inadequacy of the conditional

57

Meyer, Robert K., "Entailment", The Journal of Philosophy, 1971, p. 810 . 
relation. For Meyers a system may either "express" or "indicate" entailment. A connective indicates entailment when it is held metalogically true that $A$ entails $B$ if and only if $A \rightarrow B$ is a theorem. A system "expresses" entailment if and only if $A \rightarrow B$ means that $B$ is a logical consequence of A. Meyers analysis rests upon the semantical tool of "metavaluation." "Briefly, a metavaluation V for a logic L is simply a function from sentences of $L$ to $T$, $F$ that respects truthfunctional connectives in the usual way, but which has the property that $V(A \rightarrow B)=T$ if and only if $A \rightarrow B$ is a theorem of $L$. A logic is coherent if all its theorems come out true on all metavaluations; coherence, in view of the remarks just made, appears to be the least that one would expect of a logic that purports to express entailment."58 The system $E$ is coherent, while classical truth in functional logic is not.

The heart of the problem still remains making $A \rightarrow B$ true on any interpretation which makes A false. Meyers in fact points out the associated problem of counterfactuals mentioned in the next chapter. The results seem to be the exclusion of a counterfactual logic at the outset.

Further credibility has been given to Anderson and BeInap's 'E' by the work of Kenneth W. Collier. 59 In his paper "Physical Modalities" and the system $\mathrm{E}$, Collier has attempted to integrate Von Wright's binary modalities with the entailment forms of E. Collier

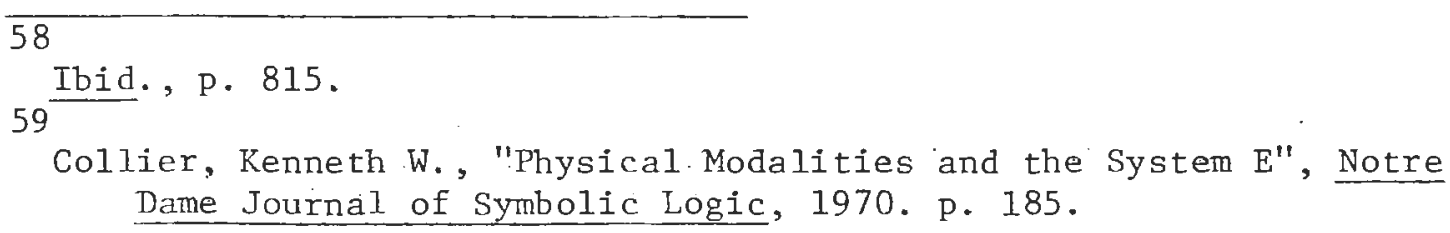


has appealed to $\mathrm{E}$ to avoid the problems of material implication found In Von Wright's own attempts. 


\section{CHAPTER Y}

(a) (t)

The purpose of this thesis wals to explicate certain fundamental features of implication with special attention to the entailment relation. Insofar as this was done, certain apparent results emerge. In the first place, insight is gained into certain elemonts of our logical locutions. Swomelly, the conditions for the establishment of an intuitively arecontable antailment relation are given. And finnlly, a constituent of the second result surfaces as a fundamental. philosophical-logical issue. That is to sity, the problem of the commonnlity of meaning between ante-

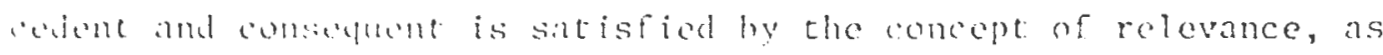
cited above.

Porhaps the most obvious signs of lngic aro the most ambigunus. The concept of implication, which is one of the most fundamental concepts of logic, has been the chief concern in this research. Three symbols have been used to represent this relation - they were the material implication sign " $\supset "$, the strict implication sign $" 3$ " and the entiliment sign, " $\rightarrow$." In each of these, certain peculiar properties are possessed.

di spocial sisniricance is the concept of consequence. The conditions for the employment of the above-mentioned symbols 1 imit the use of the respective symbols. The variance of acceptable usage suggests the following observation: the systems discussed 
in this researeh form three classes of lommlas: givon he rho

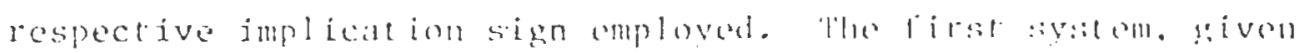

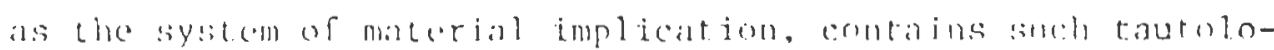

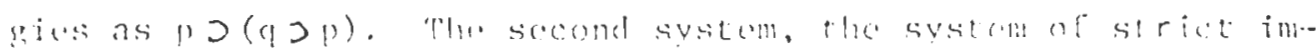
plication, is a stronger system or implication and does not contain the analogue of $p \supset\left(r_{p} p\right)$ which would be $p-3(q-3 p)$. lhe third sustom of implication. the system of entailmont, differs from the socome in a similar fashiom. lhiat is io sity, such

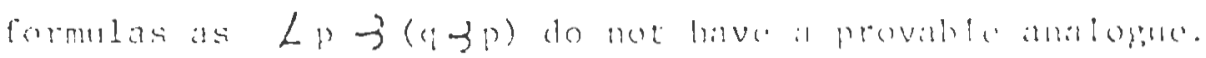

Another point of greater significance surrounds the paradoxical features of the first two classes of implication. It is unnccessary to reiterate here what has already been discussed in the appropriate sections carlier, but what needs to be mentioned is

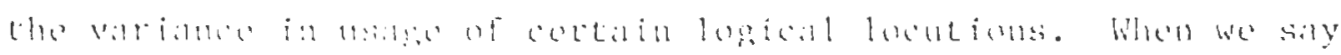
'A follows from $B^{\prime}$ we should kecp in mind the proper context, if we have an implicational scheme in mind. This does not mean one must have a set of properties say, $F_{1}, F_{2}$, $F_{3}$ for the different degrees or senses of implication. The point is simply, that even the advanced student of Joric should not forget wat the elementary texts of $10 \mathrm{gic}$ siby ol "fillacies of rolevance."

Any atcompt to incorporate meaning into lopical formolism, as with the case of the calculus of ontailment, must come had to head with the vast range of problems clustored around such a concept, as meaning. The analysis of meaning has hesu recently a common subject of inquiry in many philosophical cireles. We could not hore survey 


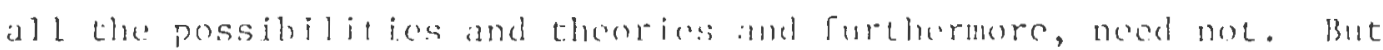

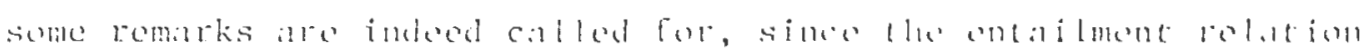
discussed entier, mploys rolevance als an essential ingredient. A rudimentary feature of concern, and olten objection, centers around the possibility of 'reaning' w' 'meanings' which have a timeless, unchanging detcrmintey. We bocone facod with the lusk of establishing the hasic form or at loast the mole, by whoh any formal reprosentative of moaning can bo assimilated into our

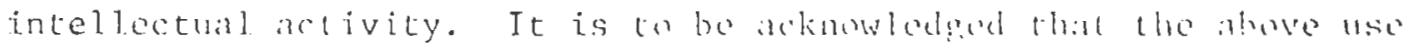
of the corms 'meaning,' 'relevance', cule, prosents mally dirlicul-. t. ics becanse of the torms' vagurnosis, as such, in goneral discourse but the rolevine points pertinent to whitilnent will bucome searer in whist lollows.

often such it topic begins by stating that such a subject is dependent on the nature of a propusil iom. How ror instance, dons

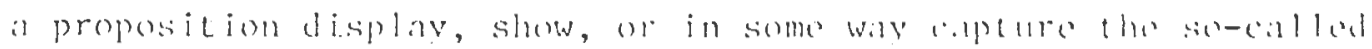
"sense" of a sentance? Indeed, if the propusitions are to be rolallod, as in the case of antocedent and consequent for the

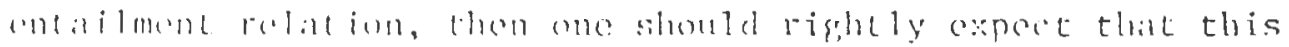
relation would be acounted for in logical theory. The analysis, however, of propositional logic procecols by the employment of nuanalyzed propositimal. variables and the use of truth-functional

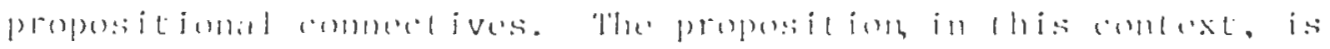
comcernod with the represition of something, true, or talse. There is then, a neod to charify how truth and falsity relate to the

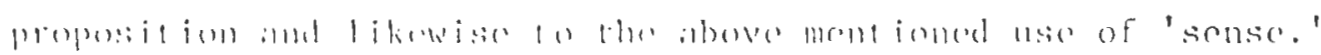


In the body of this research, the notion of a tense model of modal logic was couched upon. The tense model was formed by employing logical mulal systems between S4 and S5 with differing interprotations for hoth $M$ and $T$. In such a modol the concept of chansing truth values often appears. The question then is whether changing truth values is incompatible with the nature of a proposition and further whether chinging truth values alters the "sense" of a statement? The possibility of the alteration of sense appears excluded at the outset. If the sense, whatever this could mean, was to change over time, we would be involved in a regress of interpretation. For if the sensc changed, this change would presuppose a chanse in time: time, however, is the original falcor. The determinacy of what we are to moin by sense, is presupposed independenty of, and perhaps logically prior to the influence of time. Since we are concerned with the nature of a proposition, it becomes obvious that the relations between sense and Tense should be accounted for in a theory about the nature of a) Propusil ion.

Whitever.we are to mean then by sense, it must be determinate in time. The model which allows the values of propositions to change in time must account for the vilue assignnent of a proposition at one point in time to assume the status of an alternative assigmante. The direction suggester then is that the sense on the one hand is determinate, while the relations of propositions with respect to truth valur may vary. These relations might, of course, be only suggestive; they might be purely fictitious. Changing truth value does not mean that some logiral law may move from the realm of necessity to 
possibility; this would surely be preposterous. What is at stake here is rather the possibility of a logic. for instance, of counterfactual. conditionals. In such a logic, the value assignment is contrary to the Eactual occurrence of events, but the hyothetial still sugests possible relations. If mening is assumed to be determinate, then alternative events should still produce determinate relitions. If it is not irrational to consider alternatives in the future, then should we expect it to be irrational to consider them in the subsequent tense changes? Here we have a theory that al lows propositions to chinge value in time; yet given this operation for deny this operal ion), the proposition functions according to rules in tense logic. A logic of counterfactuals would seem to suggest that if the nature of a proposition is receptive to such a logic, then tense conditions of this sort are pertinut to the proposition itself, or at least its employment?

A real problom or objection at this point is perlaps given from the niture of a proposition. Ts the proposition which has changed value identical with the origrinal proposition? Tf the propostion is not identical in both occurronces, then the issute of changing truth values would appear to be oxcluded at the outset.

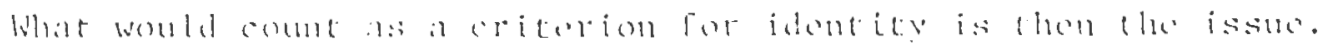
'lhe signs, that is the worls are certainly the same with the sole

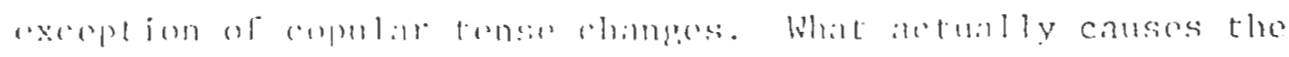
supposol champ in wallo is the factual state. The fartual state is not, hewever. the propusition but only whit is represented. 
The conditions for identity are perhaps dependent on the form of the proposition. The form of the proposition, it seems, resolves itself into subject and predicates, etc. Consider the case in which there is a change in state of a process, such that the process terminates: at the time $t_{1}, p$ is assigned the value $T$, at $t_{2}, p$ is assigned the value $F$. A logic to deal with such a change would certainly require $p$, at both $t_{1}$ and $t_{2}$, to be considered the same proposition. What such a logic must account for is in fact the mechanics. The resolution of questions of identity actually finds expression in the establishment of conditions or rules for the system. This, however, concerns rules for the relations which a proposition may enter into. What then shall give a unifled theory for entailment? On the one hand, there are serious problems to resolve from the philosophical foundations of logic. On the other hand, certain mechanical operations seem to be undeniable. The answer seems to center upon methodological considerations. The logical theory must be philosophically acceptable and yet be formally rigorous. In the process, the nature of a proposition reveals itself by showing the varlous types of relations which it may enter into. One immediate aim is to clarify the conception of 'sense' as a meaningful term about meaning. It might be helpful to speak about sentences as opposed to propositions to clarify matters. In this way, following the method of Carnap, (see below), one can speak of the proposition as the 'sense' or intension of the sentence, while leaving value assignment open as the extension. 


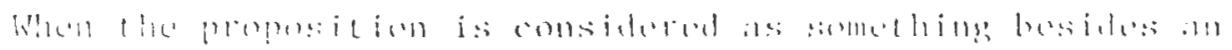

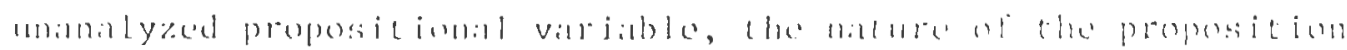
begins to show itsolf. Truth is a key point uf concern for propusitional theory. The concopts of truth, although closely allied lo the problems ol the nature of a propusition, matulatu an

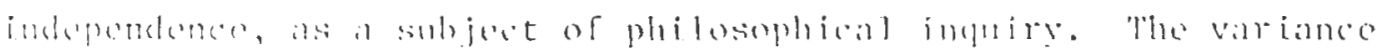
of che cuncention of truth alluws the subject to be discussed with

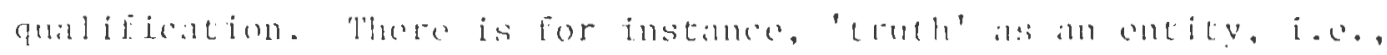
as in the case in which someone might identify the Deity with truth. On the other hand, there are more restricted usiges such as truth valuc assignments for propositions. And futther, there are methodological considerations which give truth as something denendent an dolerminate conditions of moming. Such combitions may give rules of truth, for some systoms and may allow for such distine-

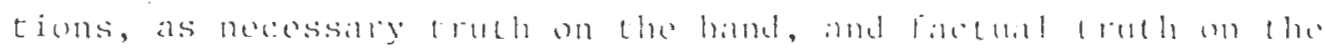
other.

This viow is simgrestive of soverat of the views of hudolph

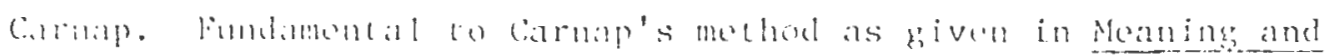
Nocessity, is the conception that properties, concepts, and quali-

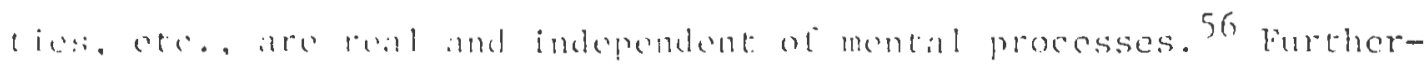

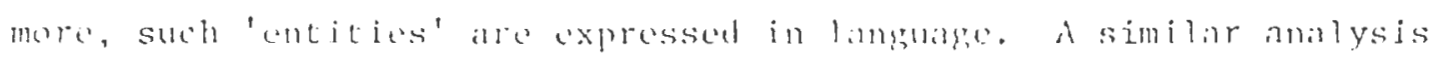
applies to proposition, especially concorning ihe olpiective status of propositions. This method of senantical analysis is developed by

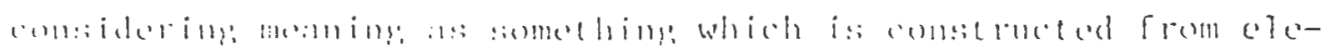

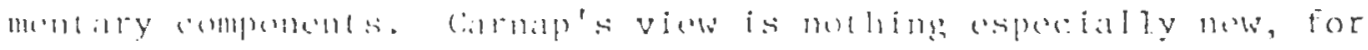
56

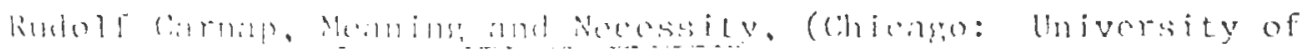

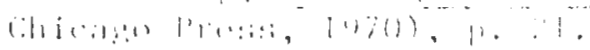




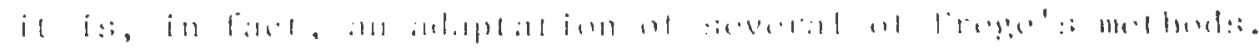

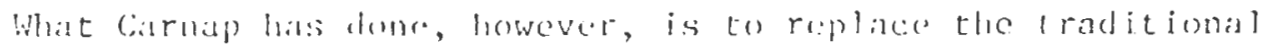

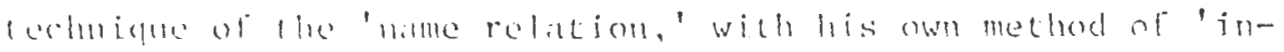

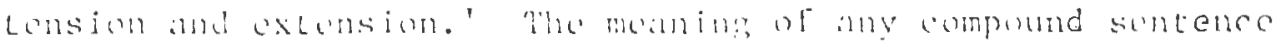
is understood as a function of component parts. The component pares themselves are logical constatiotion, which are analyzed into simpler cloments likewise siven in torms nf extension and intonsion. The extension of a sulume is its truth value,

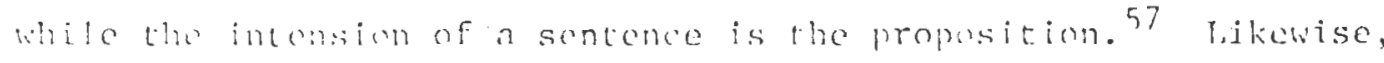

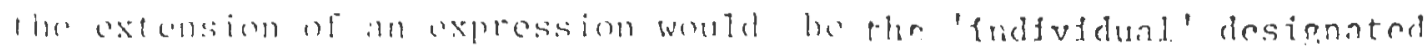

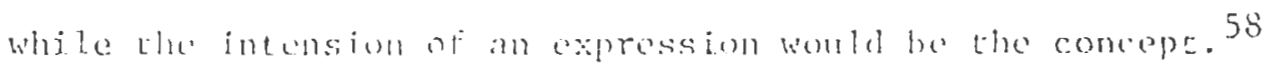
The rigor of Carnap's method sugrests a direction to a problem mentioned carlier. The notion that maning is determinate

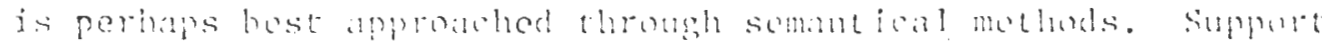

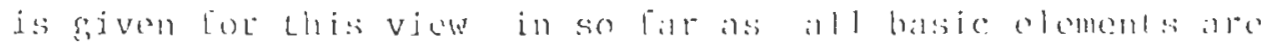

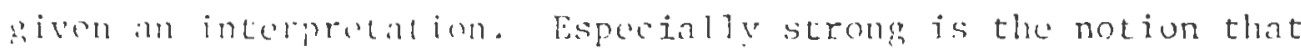
a propositim shall mintain an objectivestatus. What is purtieularly strong in such a view is that the proposition assumes

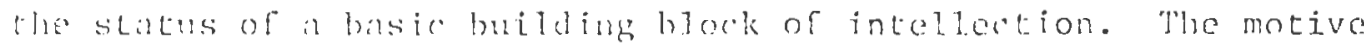

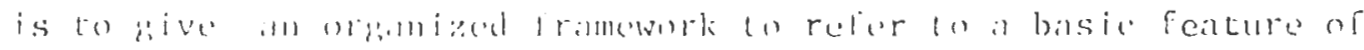

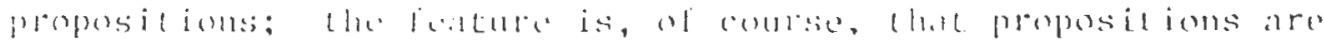
the mot acoptuble vohiche of thought. The popposition is in a

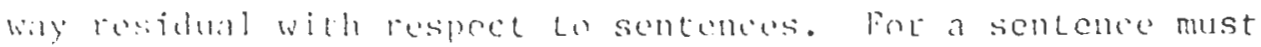
prosuppose the runtext of a languige systom and yot tio proposition is abstringed from the sentenris.

60 rfill., p. 27.

62 Ibid., r. 14. 


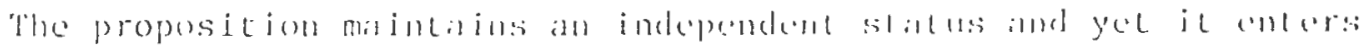
into a varicty of logical relitions. The sentonce which gives the proposition as its indonsion riay from the extensional side, for insilanec, yidel a multivalued system. 59

Carnap actually calis his method the method of 'logical analysis' in which ambiguous vague expressions are made more precise and rigorous. Any notion thus modified is done so, by 'explication.' Carnap's method, as a method in logic, embraces sommintical amalysis. The somantical methol can be contrasted with what is usually called syntax. Mintikkal, whese own semantioal mecheds are especially note-

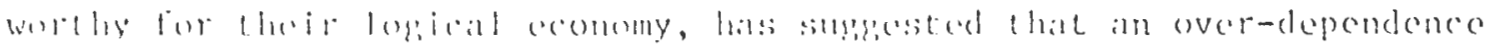
on syntactical methods will load to unnecessary limitation on achievement. "The methods best suited to increase conceptual clarity are hore, as in many other areas of lesie, the semantianl ones. (in the sonse of the torm in whel it has been applied to Carnap's and larski's stmlies.")"bol Hintikka procecels in clarirying, by sugsesting, that it is more fruichul to inquire into the conditions of truth for different kinds of sentences. This lateer point is, according to llintikka, representative of the basic mechol of semantical analysis. $6 I^{*}$

In this rescarch, the systems which employod material and strict implication, relied on deductive and axiomatio methods wich are sym-

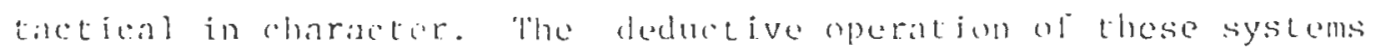

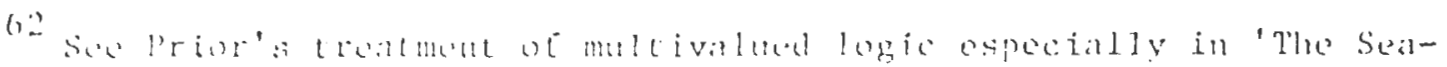
Batele 'lomorrow' argument, Prior, A.N., Formal Logic, 1962, PP. 240 250 .

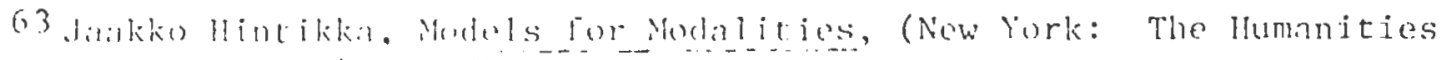
l'rensi, 1969$), 1+3$. 64 [hid.. p. 24 


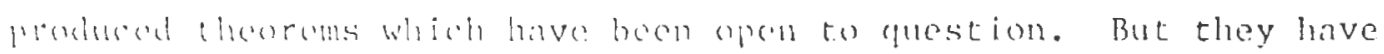
beon questionable, for wre concern in eartain points of the logical relation of implication. It may be the case that the logical. structure given in these systems has some accotable application. The calt for a stronger sense of implication, i.e., the case in which the encept of rolevance is Jesirod, an be andeved. In the system E above, the indongaios of the eirlicr systens are avoided by certain molifications. The relevined concept is established by the notion of indiees in the subscripting technique, anc by the incorporation of a notion of commonality of menning, (sec conditions given in Chapter TV, part 2). The latter is particularly interesting, in so far as, it appeals to semantical features. Phe semantics of the latter concerns entailment, "conceived of as a

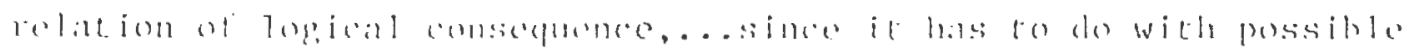

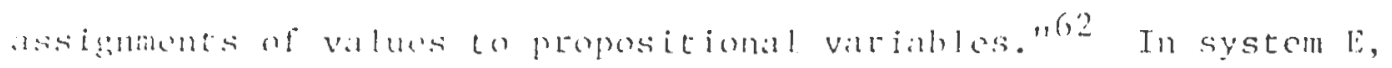
the truth of an 'entalimont' $A \rightarrow$ h, is depontent on both a specific deductive structurc and the inclusion of a concept of relevance. The later cuncept is given in terms of the sharing of a propositional variable between $\Lambda$ and $B$. Finally, in so far as the vague notion of "commonalty of moaning" is made more precise, it has, in

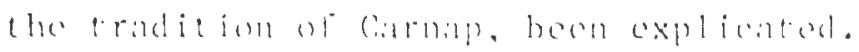

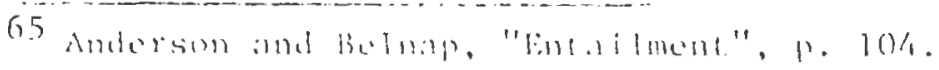




\section{BIBLIOGRAPHY}

1. Ancerson, Alan Koss and Belnap, Noel D. "The Pure Calculus of Fntailment." The Jcurnal of Symbolic Logic. v. 24 (1959).

2. Anderson, $\Lambda$ Jar. Koss and Belnap, Noe1 D. "Ertailmert." Logic and Philoscply, ed. Gary Iseminger. New York: App letonCentury Crofts, 1068.

3. Anderson, Alan Ross. "Some Open Problems Concerning the System E of Entailmer.t." Acta Philosophica Fennica, FASC, XVT: (1963).

4. Belnap, Noel D. "Entailment and Relevance." Journal of Symbolic Logic, v. 25, (June, 1960).

5. Boole, frorge. Collected Logical Works. Edj.ted by R. Pheese. vols. 1 and 2. Lasalle: the Open Court Publishing Co., .2952.

6. Bressan, Aldo. A General Interpreted Modal Calculus. New Haven: Yale University Fress, 1972.

7. Carnap, Rudolf. Neaning and Necessity. Chicago: Unfversity of Chicago Press, 1970.

8. Cohen, L.'. Diversity of Meaning. London, 1962.

9. Collter, Kenneth W. "Physical Modalities and the System F." Nctre Dame Journal of Symbclic Logic.

10. Hintikka, Jaakko. Models for Modalities. New York: Humanities Fress, 1969.

11. Fockney, Dorald J. "A Vindication of Syster E", Logique et Analyse, 1962.

12. Hughes, G.E. and Cresswe11, M.J. Modal Logic. London: Methuen and Co., I.td., 1972 .

13. Hurter, Geofrey. Metalogic. Berkeley: University of California, 1.973.

14. Iseminger, Gary, ed. Logic and Philosophy, New York: léedith Corporatior, $136 \varepsilon$.

15. Lewis, C.I. and Langford, C.H. Symbolic Logic. New York: Dover, 1959.

16. Linovev, A.A. Phflosophical Problems. Dordrecht: D. Relde1 Publishing Co., 1963. 
17. Meyer, Robert K. "Entailment." Journal of Philosophy, 1968.

18. Prior, A.N. Time and Modality. Oxford. Clarendon Press, 1957.

19. Prior, A.N. Formal Logic. Oxford: Clarendon Press, $1955-1963$.

20. Russell, Bertrand. Principles of Mathematics. New York: W.W. Norton and Co., 1903.

21. Russe11, Bertrand. Principia Mathematica. Cambridge: Cambridge University Press, 1910-1970.

22. Tarski, Alfred. Logic, Semantics, Metamathematics, Oxford: Clarendon Press, 1956.

23. Von Wright, Georg. Henrik. Logical Studies. New York: Humanities Press, 1957. 